\title{
Intermittent hypoxia confers pro-metastatic gene expression selectively through NF-kB in inflammatory breast cancer cells
}

Katrin Gutsche ${ }^{a, b, c}$, Elisa Randi ${ }^{a, b}$, Volker Blank $^{d}$, Daniel Fink ${ }^{c}$, Roland H. Wenger ${ }^{a, b}$, Cornelia Leo ${ }^{\mathrm{e} *}$, Carsten C. Scholz ${ }^{\text {a* }}$

${ }^{a}$ Institute of Physiology, University of Zurich, 8057 Zurich, Switzerland, ${ }^{b}$ Zurich Center for Integrative Human Physiology (ZIHP), University of Zurich, 8057 Zurich, Switzerland, 'Department of Gynecology, University Hospital of Zurich, 8091 Zurich, Switzerland, 'Lady Davis Institute for Medical Research, Department of Medicine \& Department of Physiology, McGill University, Montreal, Quebec, Canada, H3T 1E2, eDepartment Women and Children, Cantonal Hospital Baden, 5404 Baden, Switzerland

${ }^{*}$ These authors contributed equally to this manuscript.

Running title: $\mathrm{IH}$ regulates pro-metastatic gene expression in IBC

\section{Corresponding authors:}

Dr. Carsten Scholz Institute of Physiology

University of Zurich

Winterthurerstr. 190

8057 Zurich

Switzerland

E-mail: carsten.scholz@uzh.ch

Tel: +41446355075
PD Dr. Cornelia Leo

Department Women and Children

Cantonal Hospital Baden

Im Ergel 1

5404 Baden

Switzerland

cornelia.leo@ksb.ch

+41564863514 


\section{ABSTRACT}

Inflammatory breast cancer (IBC) is the most aggressive form of breast cancer. Treatment options are limited and the mechanisms underlying its aggressiveness are poorly understood. Intermittent hypoxia $(\mathrm{IH})$ causes oxidative stress and is emerging as important regulator of tumor metastasis. Vessels in IBC tumors have been shown to be immature, which is a primary cause of $\mathrm{IH}$. We therefore investigated the relevance of $\mathrm{IH}$ for the modulation of gene expression in IBC cells in order to assess $\mathrm{IH}$ as potential regulator of IBC aggressiveness. Gene array analysis of IBC cells following chronic $\mathrm{IH}$ (45-60 days) demonstrated increased expression of prometastatic genes of the extracellular matrix, such as tenascin-C (TNC; an essential factor of the metastatic niche) and matrix metalloproteinase 9 (MMP9), and of proinflammatory processes, such as cyclooxygenase-2 (COX-2). Investigating the oxidative stress-dependent regulation of TNC, we found a gradual sensitivity on mRNA and protein levels. Oxidative stress activated NF-E2-related factor 2 (Nrf2), cJun N-terminal kinase (JNK), c-Jun and nuclear factor $\kappa B(N F-\kappa B)$, but TNC upregulation was only dependent on NF-kB activation. Pharmacological inhibition of

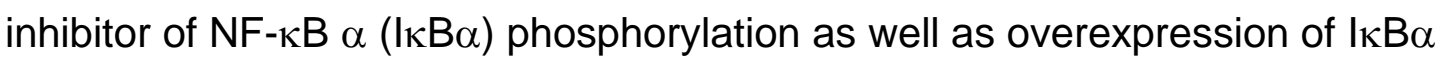
prevented TNC, MMP9 and COX-2 induction, whereas the pro-inflammatory cytokine interleukin-1 $\beta$ (IL-1 $\beta$ ) increased their expression levels. Analysis of the gene array data showed NF-kB binding sites for $64 \%$ of all upregulated genes, linking NF- $\mathrm{KB}$ with IH-dependent regulation of pro-metastatic gene expression in IBC cells. Our results provide a first link between intermittent hypoxia and pro-metastatic gene expression in IBC cells, revealing a putative novel mechanism for the high metastatic potential of IBC. 
Keywords: Intermittent hypoxia, oxidative stress, reactive oxygen species, ROS, NF$\kappa \mathrm{B}$, tenascin-C, inflammatory breast cancer

Abbreviations: ADAM19: a disintegrin and metalloproteinase 19; AP-1: activator protein-1; ARE: antioxidant response element; BSP: bisulfite sequencing PCR; CA9: carbonic anhydrase IX; CIH: chronic intermittent hypoxia; COX-2: cyclooxygenase-2; DCF: 2',7'-dichlorofluorescein; DMF: dimethyl fumarate; ECM: extracellular matrix; ER: estrogen receptor; HIF: hypoxia-inducible factor; HO-1: heme oxygenase 1; IBC:

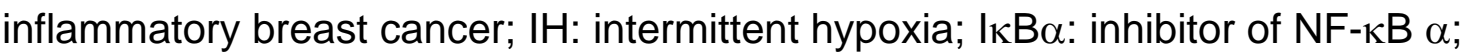
IL1A : interleukin-1 $\alpha$; IL-1 $\beta$ : interleukin-1 $\beta$; JNK: C-Jun N-terminal kinase; Keap1: kelch-like $\mathrm{ECH}$-associated protein 1; MAPK: mitogen-activated protein kinase; MMP2: matrix metalloproteinase 2; MMP9: matrix metalloproteinase 9; NAC: Nacetyl-L-cysteine; NF-kB: nuclear factor кB; Nrf2: NF-E2-related factor 2; Nrf3: NFE2-related factor 3; ROS: reactive oxygen species; SFN: sulforaphane; SHC4: Src homology 2 domain containing family member 4; SMC1: Structural Maintenance of Chromosomes-1; tBHQ: tert-butylhydroquinone; TFBS: transcription factor binding site; TNC: tenascin-C; TREM1: triggering receptor expressed on myeloid cells; XRCC2: X-ray repair complementing defective repair in Chinese hamster cells 2 


\section{INTRODUCTION}

Inflammatory breast cancer (IBC) is the most aggressive and most lethal form of primary breast cancer. While IBC is estimated to account for up to $5 \%$ of all breast cancer cases, it leads to approx. 8-10\% of all breast cancer-related deaths [1-3]. IBC presents with a diffuse tumor formation and is highly metastatic with lymph node metastases being found in almost all and distant metastases in 30\% of patients, respectively, at the time of diagnosis [2]. Treatment of IBC patients has proven to be challenging due to its rapid progression and aggressive nature $[2,4]$. The mechanisms underlying the aggressiveness of IBC are poorly understood, impeding the development of targeted therapy [2,5]. In addition, the investigation of molecular signaling pathways leading to the development of the aggressive phenotype of IBC is difficult, because of a limited availability of tumor material and with only two primary tumor-derived cell lines existing [5,6].

Tumors frequently outgrow their blood oxygen supply, leading to insufficient oxygen levels (hypoxia) and subsequent induction of angiogenesis [7]. The induced tumor vessels are often not properly developed, leading to fluctuations of blood and hence oxygen supply [8]. Oxygen levels in solid tumors are therefore dynamic, with repeated cycles of hypoxia and reoxygenation, called chronic intermittent hypoxia $(\mathrm{CIH})$ or cycling hypoxia [8]. $\mathrm{ClH}$ cycles can occur in short (minutes to hours) and long (hours to days) intervals [8,9]. High frequency cycles can be caused by differences in red blood cell flux through perturbations of the microvessel diameter, while slow frequency cycles can occur through restructuring of tumor microvessels, which has been observed in tumors to occur on a daily basis [8]. $\mathrm{ClH}$, although not directly assessed yet in IBC, likely also occurs in IBC tumors, because analysis of IBC tumor tissue showed hypoxia-dependent gene expression (carbonic anhydrase IX (CA9) induction) in $50 \%$ of the tumors and overall a higher microvessel density 
than in other breast cancer forms $[4,10,11]$. Moreover, approx. $90 \%$ of IBC tumor blood vessels are not fully developed [12]. Of note, $\mathrm{ClH}$ leads to enhanced tumor microvessel density, which could present a link to the increased microvessel density in IBC tumors [13]. In addition, $\mathrm{CIH}$ has been shown to be a stronger inducer of cancer metastases than continuous hypoxia $[14,15]$. However, the role of $\mathrm{CIH}$ in IBC progression and aggressiveness is unclear.

The median oxygen partial pressure of a tumor is $30-38 \mathrm{mmHg}$ (corresponding to $4-5 \%$ oxygen content in the gas phase), but fluctuating local oxygen gradients lead to a varying oxygenation between different tumor areas and cells, and the actual oxygen partial pressure experienced by each tumor cell depends on its proximity to vessels, local blood oxygenation, and on the oxygen consumption of surrounding cells, including tumor stroma and infiltrating immune cells $[16,17]$. Because it is not possible to accurately recreate such a complex situation in vitro, two clearly distinct normoxic and hypoxic oxygen levels were used for the investigations of the effect of $\mathrm{CIH}$ on IBC cells (normoxia: $20.9 \% \mathrm{O}_{2}$, hypoxia: $0.2 \% \mathrm{O}_{2}$ ).

$\mathrm{ClH}$ is a major source of oxidative stress due to reactive oxygen species (ROS) generation $[8,18,19]$. Oxidative stress can affect gene expression through regulation of DNA methylation and transcription factor activity $[18,20,21]$. While the mechanism of oxidative stress-dependent regulation of DNA methylation is less clear, several transcription factors have been reported to be activated by $\mathrm{IH} /$ oxidative stress, including NF-E2-related factor 2 (Nrf2), hypoxia-inducible factor (HIF), activator protein-1 (AP-1) and nuclear factor $\kappa B(N F-\kappa B)[18,21,22]$. Nrf2 is the main regulator of the cellular antioxidant response [23]. HIF is the master regulator of the transcriptional response to hypoxia but its activation by oxidative stress is still highly debated [8,24-27]. ROS have been reported to stabilize HIF-1 $\alpha$, but HIF-1 $\alpha$ was not affected by ROS in other studies $[8,18,19,24,25,27-29]$. AP-1 has been linked to the 
regulation of a wide range of cellular processes, including proliferation, migration and inflammation and has been reported to play an important role in tumor cell proliferation in the context of oxidative stress $[30,31]$. NF- $\kappa B$ is the master regulator of the cellular transcriptional response to inflammation [32,33]. In cancer cells, NF-kB activity can increase the expression of genes that promote proliferation, invasiveness, metastasis and apoptosis [34,35].

The extracellular matrix (ECM) plays an important role in the development and progression of breast cancer [36]. For example, the matrix metalloproteinases 2 and 9 (MMP2, MMP9) and a disintegrin and metalloproteinase 19 (ADAM19) are remodeling enzymes of the ECM and play a major part in the development of tumor metastasis and invasion $[36,37]$. Tenascin-C (TNC), a large hexameric ECM glycoprotein, is highly expressed during development, almost absent during postnatal live, but re-expressed in case of injury and in the onset of tumorigenesis [38]. Increased expression of TNC has been related to poor prognosis, local and distant recurrence in breast carcinomas and metastasis formation [36,39]. Of note, TNC has been shown to be an essential factor of the metastatic niche [36].

In the current study, we investigated the impact of $\mathrm{IH}$ and the resulting oxidative stress on transcriptional regulation in IBC cells. We provide evidence that $\mathrm{ClH}$ and oxidative stress are important regulators of pro-metastatic gene expression specifically in IBC cells. Investigation of the underlying mechanism of upregulated TNC gene expression showed that it is dependent on NF-kB activation but not on DNA methylation, Nrf2, AP-1 and HIF. Furthermore, $64 \%$ of all $\mathrm{CIH}$-upregulated prometastatic genes can be regulated by NF- $\mathrm{kB}$. These data provide a mechanistic link between intermittent hypoxia and pro-metastatic gene expression in IBC cells, contributing novel insights into the regulation of IBC aggressiveness. 


\section{MATERIAL AND METHODS}

\section{Reagents}

Tert-butylhydroquinone (30 $\mu \mathrm{M})$ (tBHQ; Sigma-Aldrich, St Louis, MO, USA), dimethyl fumarate (40 $\mu \mathrm{M})$ (DMF; Sigma-Aldrich), BAY11-7082 (12.5 $\mu \mathrm{M}, 25 \mu \mathrm{M})$ (Selleck, Houston, TX, USA), $\mathrm{H}_{2} \mathrm{O}_{2}(100 \mu \mathrm{M}, 500 \mu \mathrm{M})$ (Sigma-Aldrich) and 2',7'-

dichlorodihydrofluorescein diacetate $(10 \mu \mathrm{M})\left(\mathrm{H}_{2}\right.$ DCFDA; Invitrogen, Thermo Fischer Scientific, Waltham, MA, USA) were dissolved in ethanol. L-Sulforaphane (10 $\mu \mathrm{M})$ (SFN; Sigma-Aldrich) and SP600125 (10 $\mu \mathrm{M}, 20 \mu \mathrm{M})$ (Selleck) were dissolved in DMSO and N-acetyl-L-cysteine (3 mM, 20 mM) (NAC; Sigma-Aldrich) was dissolved in $\mathrm{H}_{2} \mathrm{O}$. IL-1 $\beta$ (2 ng/ml) (R\&D Systems, Minneapolis, MN, USA) was dissolved in $0.1 \%$ BSA in PBS.

\section{Cell culture and treatments}

The human triple-negative IBC breast cancer cell line SUM149PT was kindly provided by Rachael Natrajan (London, UK) and was used for all subsequent cell culture experiments if not otherwise indicated. SUM149PT cells were cultured in equal parts of high-glucose DMEM (Sigma-Aldrich) and Ham's F-12 Nutrient Mixture (Gibco, Thermo Fischer Scientific, Waltham, MA, USA), supplemented with $5 \%$ heatinactivated fetal bovine serum (FBS), $1 \mu \mathrm{g} / \mathrm{ml}$ hydrocortisone (Sigma-Aldrich), 5 $\mu \mathrm{g} / \mathrm{ml}$ human insulin (Sigma-Aldrich), $100 \mathrm{U} / \mathrm{ml}$ penicillin and $100 \mu \mathrm{g} / \mathrm{ml}$ streptomycin (Sigma-Aldrich). Reagents were diluted to the required concentration in the appropriate medium without FBS and supplements. Cells were seeded at $70-80 \%$ confluency. BAY11-7082, SP600125 and N-acetyl-L-cysteine were added to the cells $1 \mathrm{~h}$ before addition of $\mathrm{tBHQ}$. Normoxic experiments were performed in a humidified atmosphere containing $20.9 \% \mathrm{O}_{2}(131.8 \mathrm{mmHg})$ and $5 \% \mathrm{CO}_{2}(35.7 \mathrm{mmHg})$ in a cell 
culture incubator (Binder, Tuttlingen, Germany). Hypoxic experiments were carried out in a humidified atmosphere containing $0.2 \% \mathrm{O}_{2}(1.26 \mathrm{mmHg})$ and $5 \% \mathrm{CO}_{2}$ in a gas-controlled glove box (Invivo2 400, Baker Ruskinn, Bridgend, UK) as previously described [40].

\section{mRNA analysis and data deposition}

The RNeasy mini kit (Qiagen, Hilden, Germany) was used for total RNA extraction for the Affymetrix gene array analysis according to manufacturer's protocol. Affymetrix Human Gene 2.1 ST strip arrays were used to analyze transcript levels of one biological replicate of untreated cells and of cells cultured for 45 days in $\mathrm{ClH}$. The data were deposited in Gene Expression Omnibus (GEO;

http://www.ncbi.nlm.nih.gov/geo/) and are accessible through the ID GSE81416 (reviewers access:

http://www.ncbi.nlm.nih.gov/geo/query/acc.cgi?token=ihgnacgezfkxlil\&acc=GSE8141 6). For validation of the Affymetrix gene array results, three biological replicates of untreated cells and cells that were cultured for 45-60 days in normoxia or $\mathrm{ClH}$ conditions were analyzed by RT-qPCR as previously described [41]. The relative mRNA expression was calculated using the $\Delta \Delta C_{t}$ formula. U6 snRNA served as control gene and values were normalized to the average values of normoxic controls. For all further experiments, total cellular RNA was extracted as previously described [42]. Primer sequences were listed in Supplementary Table S3. mRNA copy numbers were calculated by comparison with serial dilutions of a calibrated standard, calculated relative to $U 6$ snRNA levels and normalized to the starting time point if not otherwise indicated. 
For the analysis of the Affymetrix gene array results, protein coding genes, as listed in the National Center for Biotechnology Information (NCBI) Reference Sequence (RefSeq) database, with $\geq 4$-fold increased transcript levels were used for bioinformatic analyses with MetaCore (https://portal.genego.com/) from Thomson Reuters. Enrichment analysis according to standard settings of the software was performed to rank the most relevant cellular processes. $p$ values were calculated as -log10. To analyze literature-based transcriptional regulations, the "build network" option with the algorithm for "transcription regulation" was applied. In order to link single genes to the matrisome, analysis was performed via the matrisome project for each upregulated gene (http://matrisomeproject.mit.edu/proteins/) [43]. For detection of conserved transcription factor binding sites (TFBS), the web-based software oPOSSUM version 3 (http://opossum.cisreg.ca/oPOSSUM3/) was used [44-46]. The matrices of TFBS profiles included in oPOSSUM-3 were obtained from the 2010 release of the JASPAR database (http://jaspar.genereg.net) [47]. For detection of TFBS in the TNC promoter, the UCSC genome browser (http://genome.ucsc.edu/) was searched with the genome assembly released in February 2009 [48]. Further, the Swissregulon (http://swissregulon.unibas.ch/fcgi/sr) and the JASPAR databases were searched [49].

\section{Protein detection and quantification}

Proteins were extracted from cells using $0.4 \mathrm{M} \mathrm{NaCl}, 1 \%$ Nonidet P- $40,10 \mathrm{mM}$ Tris$\mathrm{HCl}$ (pH 8.0), $1 \mathrm{mM}$ EDTA, $1 \mathrm{mM}$ dithiothreitol, $1 \mathrm{mM}$ phenylmethylsulfonyl fluoride, 1 mM sodium-orthovanadate and protease inhibitor cocktail (P2714, Sigma-Aldrich). Equal amounts of protein were separated by SDS-PAGE, transferred to nitrocellulose membranes and detected with antibodies against HIF-1 $\alpha$ (BD Transduction Laboratories, Allschwil, Switzerland); $\beta$-actin (Sigma-Aldrich); SMC1 (Abcam, 
Cambridge, UK); tenascin-C (H-300, Santa Cruz Biotechnology, Dallas, TX, USA); Nrf2 (H-300, Santa Cruz Biotechnology); $\alpha$-tubulin (Sigma-Aldrich); c-Jun, phospho-

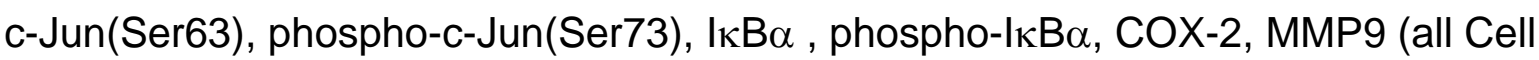
Signaling Technologies, Danvers, MA, USA); and Nrf3 [50]. Detection of primary antibodies and recording of chemiluminescence were carried out as previously described [40]. Quantification of immunoblotting signals was performed using ImageJ $1.48 \mathrm{v}$ (http://imagej.nih.gov/ij) or as previously described [40]. Values were normalized to the respective loading control and to the average values of normoxic controls if not otherwise indicated.

\section{Detection of secreted TNC by enzyme-linked immunosorbent assay (ELISA)}

SUM149PT cell treatments were performed in equal volumes of medium and medium was collected following $24 \mathrm{~h}$ of tBHQ treatment and frozen at $-20^{\circ} \mathrm{C}$ until analysis. Secreted tenascin-C was detected with the human Tenascin-C Large (FNIII-C) ELISA Kit (IBL, Japan) as per manufacturer's description.

\section{siRNAs and plasmids}

For siRNA experiments, cells were seeded to reach $60 \%$ confluency on the day of transfection. Nrf2 siRNA (ON-TARGET plus Human NFE2L2 siRNA, SMART pool), Nrf3 siRNA (ON-TARGET plus Human NFE2L3 siRNA, SMART pool), c-Jun siRNA (ON-TARGET plus Human JUN siRNA, SMART pool) and non-target siRNA (ONTARGET plus Non-targeting Pool) were purchased from Dharmacon (GE Healthcare, Lafayette, CO, USA) and transfected using Lipofectamine 2000 (Invitrogen) and OptiMEM (GIBCO) according to manufacturers' protocols. For plasmid transfections, cells were seeded to reach $70 \%$ confluency on the day of transfection. NC16 pcDNA3.1 FLAG Nrf2 was a gift from Randall Moon (Addgene plasmid \# 36971) [51], pCMV4-3 
$\mathrm{HA} / \mathrm{I}_{\kappa} \mathrm{B} \alpha$ was a gift from Warner Greene (Addgene plasmid \# 21985) [52] and pcDNA3.1-hNFE2L3 has previously been published [50]. Treatments were performed after $24 \mathrm{~h}$ of transfection.

\section{DCF assay}

SUM149PT cells were seeded in 96-well plates and incubated with $10 \mu \mathrm{M} \mathrm{H}_{2} \mathrm{DCFDA}$ for 30 min in the dark. Subsequently, specific treatments were performed and fluorescence was measured using a 96-well fluorescence photometer (Infinite 200Pro, Tecan, Männedorf, Switzerland). For combined treatments with tBHQ and NAC, cells were pretreated for $1 \mathrm{~h}$ with NAC. Results were calculated as increase in fluorescence per well ((Ftx - Ft0) / Ft0*100), where Ftx = fluorescence at a certain time point and Ft0 = fluorescence at 0 min [53]. For hypoxia-reoxygenation experiments, 96-well plates were incubated for $24 \mathrm{~h}$ in $0.2 \%$ oxygen. Cells were incubated with $\mathrm{H}_{2}$ DCFDA inside the hypoxia workstation and fluorescence measurements were performed immediately thereafter. For measurements during hypoxic incubation, plates were sealed at measurement time points with oxygen impenetrable foils (Brand $\mathrm{GMBH}+\mathrm{CO}$ KG, Wertheim, Germany) within the hypoxia workstation and measurements were performed as described.

\section{Statistical analyses}

If not otherwise indicated, results are presented as mean values \pm standard error of the mean (SEM) of at least three independent experiments. Statistical analyses were performed using Student's t-test and one-way ANOVA or two-way ANOVA where appropriate. P-values $<0.05$ were considered statistically significant. 


\section{RESULTS}

\section{Chronic intermittent hypoxia increases pro-metastatic gene expression in}

inflammatory breast cancer cells.

In order to investigate the impact of $\mathrm{CIH}$ on IBC, the primary tumor-derived IBC cell line SUM149PT was cultured for 45 days in CIH conditions ( 15 cycles of hypoxia/reoxygenation; Fig. 1A) and gene expression was assessed by whole genome microarray hybridization. Using a four-fold difference relative to control as threshold for relevant gene regulation, 37 genes were identified to be upregulated and 51 genes to be downregulated in response to $\mathrm{ClH}$. Analysis of associations of the upregulated genes with cellular processes via MetaCore (https://portal.genego.com/) showed that these genes are primarily involved in the regulation of the ECM (Fig. 1B). 13 out of the 37 upregulated genes were linked to the "matrisome", which is composed of ECM and ECM-associated proteins (Supplementary Table S1) [43]. A second relevant process associated with $\mathrm{ClH}$ upregulated gene expression was inflammation (Fig. 1B).

The $\mathrm{ClH}$ experiment was repeated to validate the expression levels of 10 out of the 37 upregulated genes. TNC, MMP2, MMP9 and ADAM19 were chosen because these proteins are important components and remodeling enzymes of the ECM, and since they have previously been shown to play a major role in tumor invasion and metastasis $[36,37]$. Triggering receptor expressed on myeloid cells (TREM1), interleukin-1 $\alpha$ (IL1A) and cyclooxygenase-2 (COX-2; gene name: PTGS2, prostaglandin $\mathrm{G} / \mathrm{H}$ synthase 2) have been linked before to inflammatory processes, and COX-2 has been associated with a more aggressive breast cancer phenotype [2]. NF-E2-related factor 3 (Nrf3, gene name: NFE2L3) is a homolog of the transcription factor Nrf2 and might be part of the oxidative stress response [54]. Src homology 2 domain containing family member 4 (SHC4) plays a critical role in 
migration of metastatic melanomas and potentially in the response to oxidative stress-induced DNA damage; and a SNP in X-ray repair complementing defective repair in Chinese hamster cells 2 (XRCC2), which is involved in homologous recombination DNA repair, was linked to spontaneous breast cancer development [55-57]. We analyzed the expression pattern of these genes in response to hypoxia, reoxygenation (both part of cycle 1 of the $\mathrm{ClH}$ experiment; Fig. 1A) and $\mathrm{CIH}(15-20$ cycles; Fig. 1A). All genes except MMP9 demonstrated a significant upregulation following $\mathrm{CIH}$ (Fig. 2A). But also MMP9 showed an upregulation in response to $\mathrm{CIH}$ in all three independent experiments, only with a higher degree of variability. To analyze the expression patterns further, we directly compared the observed induction factors of the different treatments to each other and identified three differentially regulated groups (Fig. 2B). Group I showed only upregulated gene expression in response to $\mathrm{ClH}$, while group II genes were already increased in response to a single reoxygenation stimulus (Fig. 2B), and group III was upregulated by all three treatments (Fig. 2B). These findings indicate that some of these genes are only sensitive to a higher oxidative stress such as $\mathrm{CIH}$ (group I), while others are already upregulated by a single reoxygenation event (group II). In group III, we most likely observed overlapping regulation between hypoxia and the oxidative stress response. Of note, no increase in prototypical HIF target genes (e.g. CA9 or glycolytic enzymes) was observed in the gene array following $\mathrm{CIH}$, indicating that HIFdependent gene expression was not present in our $\mathrm{ClH}$ conditions at the time of analysis. In order to determine if $\mathrm{CIH}$ also led to increased protein levels, we determined TNC protein expression following the three different treatments. TNC protein expression followed the same pattern as its mRNA, with no upregulation in response to hypoxia or a single reoxygenation event but with a significant increase following 15 and 20 cycles of $\mathrm{CIH}$ (Fig. 2C, D). 
Overall, these results demonstrate that $\mathrm{CIH}$ increases pro-metastatic gene expression in IBC cells. In addition, we identified three distinct groups of regulated genes, indicating a differential sensitivity to oxidative stress and hypoxia among the investigated genes. The observed changes on mRNA levels translated into protein expression, indicating functional relevance.

\section{Tenascin-C expression demonstrates a gradual sensitivity to increasing oxidative stress levels specifically in IBC cells}

We next investigated the underlying mechanism of the $\mathrm{ClH}$-dependent increase in pro-metastatic gene expression. We focused on TNC expression because its mRNA and protein levels were specifically upregulated in response to $\mathrm{ClH}$ but not to hypoxia, demonstrating that its regulation depends on repeated reoxygenation events (Fig. 2). Furthermore, TNC has been linked to breast cancer development, it plays a major role in tumor progression and metastasis, and it has been shown to be an essential factor of the metastatic niche [36]. Because $\mathrm{CIH}$ is a well-established oxidative stress inducer and likely leads to a more severe oxidative stress than a single reoxygenation event $[8,18,58]$, we aimed to investigate the effect of increasing oxidative stress conditions on TNC-dependent gene expression. First, we compared the potential of different stimuli, a single hypoxia/reoxygenation phase, hydrogen peroxide $\left(\mathrm{H}_{2} \mathrm{O}_{2}\right)$ and $t B H Q$, to induce oxidative stress in SUM149PT cells using the DCF assay (Fig. 3A-C). Within cells, tert-butylhydroquinone (tBHQ) autooxidizes via an intermediate step as semiquinone to tert-butylquinone in an oxygen-dependent manner, forming two oxygen radicals per each tBHQ molecule [59]. Hypoxia/reoxygenation led to a short but significant increase in DCF fluorescence at early time points ( 0.5 h) (Fig. 3A), while $100 \mu \mathrm{M} \mathrm{H}_{2} \mathrm{O}_{2}$ led to a prolonged, plateauing increase in fluorescence over $4 \mathrm{~h}$ (Fig. 3B). $30 \mu \mathrm{M} \mathrm{tBHQ}$ induced a steady increase 
in fluorescence over $4 \mathrm{~h}$ and the observed signal was up to 4 -fold higher than with single hypoxia/reoxygenation or $\mathrm{H}_{2} \mathrm{O}_{2}$ (Fig. 3A-C). Hypoxia did not increase DCF fluorescence, indicating that the reoxygenation phase following hypoxic incubation is necessary for a detectable increase in ROS levels (Supplementary Fig. 1A \& B). This established the following order of ROS induction by these treatments: tBHQ ( $30 \mu \mathrm{M})$ $>\mathrm{H}_{2} \mathrm{O}_{2}(100 \mu \mathrm{M})>$ single reoxygenation.

DCF assay analysis of SUM149PT cells following the CIH experiment showed that there was no further increased fluorescence upon hypoxia/reoxygenation in comparison to cells that had not been cultivated in $\mathrm{ClH}$ (Supplementary Fig. S1C). This indicates that long-term cultivation of SUM149PT cells in ClH does not change the intrinsic cellular ROS production in response to reoxygenation.

Next, we investigated the impact of the different ROS sources on TNC mRNA and protein expression. Hypoxia/reoxygenation led to a significant but short and transient increase in TNC mRNA levels at 2 and $4 \mathrm{~h}$ (Fig. 3D), while $\mathrm{H}_{2} \mathrm{O}_{2}$ significantly induced TNC mRNA at 4-8 h (Fig. 3E) and tBHQ at $9 \mathrm{~h}$ and $24 \mathrm{~h}$ (Fig. $3 F$ ), with 5 to 9 -fold higher TNC mRNA levels following tBHQ treatment compared to the other treatments (Fig. 3D-F). On the protein level, hypoxia/reoxygenation neither induced TNC (Fig. 3G) nor activated the positive control for oxidative stress, the redox-sensitive transcription factor Nrf2 (data not shown). CA9 mRNA levels and HIF-1 $\alpha$ protein levels were used as positive controls for hypoxia (Fig. 3G, Supplementary Fig. S1D). In turn, $\mathrm{H}_{2} \mathrm{O}_{2}$ increased TNC protein levels significantly after $6 \mathrm{~h}$ (Fig. 3H). Nrf2 protein was stabilized and its target gene heme oxygenase 1 (HO-1) was elevated in response to $\mathrm{H}_{2} \mathrm{O}_{2}$ treatment (Fig. 3H, Supplementary Fig. S1E). tBHQ treatment led to a strongly increased protein expression after $9 \mathrm{~h}$ and 24 h (Fig. 3l). Nrf2 protein levels and HO-1 mRNA were also elevated by tBHQ (Fig. 3I, 
Supplementary Fig. S1F). Of note, the observed differences of activated Nrf2 protein levels between the treatments are in agreement with the differences of ROS measured by the DCF assay ( $\mathrm{tBHQ}>\mathrm{H}_{2} \mathrm{O}_{2}>$ single reoxygenation), further supporting a differential ROS induction between the treatments (Fig. 3A-C, G-I). tBHQ treatment also led to an increased secretion of TNC protein (Fig. 3J), further indicating the functional relevance of the observed TNC regulation.

In order to test if the observed ROS-dependent regulation of TNC also occurs in triple-negative non-IBC breast cancer cells, we investigated the effect of tBHQ treatment on TNC expression in the MDA-MB-231 and MDA-MB-468 cell lines. tBHQ treatment led to a significant increase in Nrf2 protein and HO-1 mRNA levels in MDAMB-231 cells, indicating effective ROS induction, but did not increase TNC mRNA or protein levels (Supplementary Fig. S2A-C). In MDA-MB-468 cells, tBHQ treatment also led to increased Nrf2 protein levels but did not upregulate TNC protein (Supplementary Fig. S2D). These data indicate that the observed ROS-dependent regulation of TNC is specific to IBC cells.

Overall, TNC expression shows a gradual sensitivity to ROS levels specifically in inflammatory breast cancer cells, indicating that $\mathrm{ClH}$ increases TNC expression through increasing oxidative stress.

\section{Antioxidant treatment prevents oxidative stress-mediated TNC induction}

We next sought to determine if the observed TNC induction was directly dependent on ROS. SUM149PT cells were pre-treated with the antioxidant NAC for $1 \mathrm{~h}$ followed by the addition of tBHQ. NAC prevented tBHQ-mediated ROS production (Fig. 4A) as well as $\mathrm{tBHQ}$-mediated upregulation of TNC protein levels (Fig. 4B). These results demonstrate that regulation of TNC expression is directly linked to oxidative stress and can be prevented by antioxidant treatment. 


\section{Oxidative stress-dependent TNC induction is independent of Nrf2 and Nrf3}

DNA methylation is frequently involved in chronic changes of gene expression and can be regulated by oxidative stress [20]. Therefore, we first investigated a potential impact of $\mathrm{CIH}$ on DNA methylation as a molecular mechanism for the regulation of TNC expression. Although CpG-rich regions were identified in the TNC promoter and in the first untranslated exon of $T N C$, no difference in methylation following $\mathrm{CIH}$ was observed in the TNC promoter by methylation-specific PCR (MSP) (Supplementary Fig. S3) nor in the TNC promoter or the first untranslated exon of TNC by bisulfite sequencing PCR (BSP) (data not shown).

A main transcription factor activated by oxidative stress is Nrf2 [23]. Nrf2 protein was stabilized and Nrf2-dependent target genes were increased in SUM149PT cells following $\mathrm{H}_{2} \mathrm{O}_{2}$ and tBHQ treatment (Fig. 3H, I, Supplementary Fig. S1E, F). In addition, in response to $\mathrm{ClH}$ we observed elevated Nrf3 mRNA levels (Fig. 2A). Nrf3 belongs to the same Cap'n'Collar transcription factor family as Nrf2 and has also been linked to the cellular antioxidant response [54]. Furthermore, the TNC promoter can be regulated by $\mathrm{BACH} 1$, a transcriptional suppressor binding antioxidant response elements (AREs) (Fig. 5A) [60]. Following oxidative stress, BACH1 does not suppress ARE-dependent transcription anymore [60], allowing e.g. Nrf2 or Nrf3 to bind instead (Fig. 5A). Therefore, we transiently knocked down Nrf2 and/or Nrf3 in SUM149PT cells, followed by tBHQ treatment. No significant difference in $\mathrm{tBHQ}$-dependent TNC induction was detected with single or combined Nrf2 and Nrf3 knockdown (Fig. 5B), while HO-1 induction, a known direct Nrf2 target gene, was significantly down-regulated (Fig. 5C) [23]. Interestingly, knockdown of Nrf3, which had previously been reported to be capable of both inducing and repressing gene transcription [61], increased $\mathrm{HO}-1$ expression, indicating that $\mathrm{Nrf3}$ is 
a repressor of ROS-induced HO-1 expression (Fig. 5C). Single and combined knockdown or overexpression of Nrf2 and Nrf3 showed no major effect on basal TNC gene expression (Supplementary Fig. S4). In addition, the effect of two chemical Nrf2 activators on TNC expression was tested, SFN and DMF. SFN and DMF mediate stabilization and nuclear translocation of Nrf2 by modulating the inhibitory protein of Nrf2, kelch-like ECH-associated protein 1 (Keap1) [62,63]. SUM149PT cells were treated with $10 \mu \mathrm{M}$ SFN and samples were collected for up to $24 \mathrm{~h}$. No change in TNC mRNA expression was detected, while the induction of HO-1 $6 \mathrm{~h}$ after treatment demonstrated efficient Nrf2 activation (Fig. 5D). Treatment with $40 \mu \mathrm{M}$ DMF caused only a slight elevation in TNC mRNA levels after $24 \mathrm{~h}$, but showed a significant HO-1 induction from $3 \mathrm{~h}$ to $9 \mathrm{~h}$ (Fig. 5E). Increased TNC mRNA levels through DMF stimulation correlated with increased ROS levels while SFN caused no significant ROS production and no elevated TNC mRNA levels (Supplementary Fig. S5). Of note, the increase in ROS following DMF treatment was much lower than the ROS levels measured after $\mathrm{H}_{2} \mathrm{O}_{2}$ treatment and negligible compared to the ROS production caused by tBHQ (Fig. 3B, C, Supplementary Fig. S5B).

Overall, these results demonstrate that oxidative stress-dependent TNC induction is independent of Nrf2 and Nrf3.

\section{Oxidative stress-dependent TNC induction is independent of JNK and c-Jun activity.}

Another transcription factor activated by oxidative stress and IH is AP-1, which is regulated by mitogen-activated protein kinase (MAPK) signaling $[18,21,30]$. AP-1 is a dimeric protein that can be composed of several different subunits of which the major protein subfamilies are Jun (c-Jun, JunB, JunD) and Fos (c-Fos, FosB, Fra-1, Fra-2)

[30]. The TNC promoter contains ChIP-based binding sites for AP-1 subunits such as 
C-Jun (Fig. 5A). tBHQ increased over a time course of $24 \mathrm{~h}$ c-Jun phosphorylation on serine 63 and 73, which enhances c-Jun transcriptional activity (Fig. 6A) [30]. In addition, total c-Jun protein levels were increased (Fig. 6A). C-Jun has been reported to be phosphorylated on serine 63 and 73 by the MAPK c-Jun N-terminal kinase (JNK) [30]. Therefore, we next investigated if tBHQ-dependent c-Jun phosphorylation could be prevented by the JNK inhibitor SP600125. One hour pre-treatment with SP600125 blocked tBHQ-dependent C-Jun phosphorylation (Fig. 6B), indicating that $\mathrm{tBHQ}$ activates the MAPK signaling cascade at the level of or upstream of JNK. However, the JNK inhibitor did not prevent tBHQ-mediated TNC induction (Fig. 6C). Furthermore, siRNA-mediated knockdown of c-Jun did also not significantly affect tBHQ-dependent TNC induction (Fig. 6D). These results show that oxidative stress activates MAPK signaling and c-Jun in IBC cells but the oxidative stress-dependent increase of TNC is independent of this mechanism.

\section{Oxidative stress-dependent TNC induction is mediated by NF-кB.}

A further transcription factor activated by oxidative stress is NF-kB, which also has a putative binding site in the TNC promoter (Fig. 5A). Hence, we next tested if tBHQ can activate NF- $\mathrm{KB}$ in IBC cells and treated SUM149PT cells with tBHQ over a $24 \mathrm{~h}$ time course. This led to a time-dependent decrease of inhibitor of NF-kB $\alpha(\mathrm{I} \kappa \mathrm{B} \alpha)$ protein levels (Fig. 7A), demonstrating activation of the NF-kB signaling pathway. Pre-treatment with BAY11-7082, which prevents phosphorylation and subsequent degradation of $I_{\kappa} B \alpha$ [64], blocked the tBHQ-dependent decrease of $I_{\kappa} B \alpha$ (Fig. 7B), indicating that $\mathrm{tBHQ}$-mediated oxidative stress activates the NF-kB signaling pathway at the level of or upstream of $I_{\kappa} B \alpha$ phosphorylation. Inhibitor treatment $1 \mathrm{~h}$ prior to the $\mathrm{tBHQ}$ stimulus abrogated the increase in TNC expression (Fig. $7 \mathrm{C}$ ), 
indicating that NF- $\mathrm{kB}$ regulates oxidative stress-mediated TNC induction. We expanded our investigations further to MMP9 and COX-2, which had shown increased expression in response to $\mathrm{CIH}$ (Fig. 2A, B) and which were upregulated in response to $\mathrm{tBHQ}$ treatment (Supplementary Fig. S6A). Pre-treatment with BAY117082 abrogated the $\mathrm{tBHQ}$-dependent increase of MMP9 and attenuated $\mathrm{tBHQ}$ dependent COX-2 upregulation (Fig. 7C). Overexpression of $I_{\kappa} B \alpha$ also prevented the oxidative stress-dependent induction of TNC, MMP9 and partly of COX-2, overall confirming their regulation by the NF- $\mathrm{BB}$ signaling pathway (Fig. 7D). $\mathrm{H}_{2} \mathrm{O}_{2}$, which induced TNC mRNA and protein expression (Fig. 3E, H), also increased NF- $\kappa B$ activity in an NF-אB dependent luciferase reporter gene assay in SUM149PT cells, indicating that the observed ROS-dependent NF- $\mathrm{BB}$ activity in IBC cells is a general consequence of oxidative stress and not specific to the $\mathrm{tBHQ}$ stimulus (Supplementary Fig. S6B).

Treatment with the major pro-inflammatory cytokine IL-1 $\beta$, one of the bestcharacterized NF- $\mathrm{NB}$ activating stimuli $[64,65]$, showed a decrease of $I_{\kappa} \mathrm{B} \alpha$ levels at 30 min and a strong increase in TNC and COX-2 protein levels from 3-24 $\mathrm{h}$ and of MMP9 from 9-24 h (Fig. 7E). Analysis of breast cancer transcriptomic datasets revealed a significant, positive correlation between TNC and nuclear factor $\kappa$ B p105 subunit levels (Supplementary Fig. S7). Together with the previous results, this demonstrates that oxidative stress-induced TNC, MMP9 and COX-2 expression is regulated by $\mathrm{NF}-\kappa \mathrm{B}$. Interestingly, when we investigated our $\mathrm{CIH}$ gene array results for transcription factor binding sites and known regulation by transcription factors using oPOSSUM and MetaCore (http://opossum.cisreg.ca/oPOSSUM3/ and https://portal.genego.com/), 64\% of all upregulated genes showed a possible

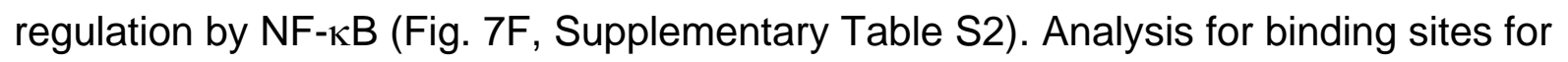


AP-1 and Nrf2 revealed a putative regulation of $33 \%$ by Nrf2 and of $83 \%$ by AP-1 with $30.6 \%$ of these genes showing overlapping regulation by Nrf2, AP-1 and NF-kB (Supplementary Fig. S8).

Overall, our results demonstrate that the oxidative stress-dependent increase of several pro-metastatic genes is specifically regulated by NF-kB and that this transcription factor might also play an important role in the upregulation of further pro-metastatic genes in IBC cells in response to $\mathrm{CIH}$. 


\section{DISCUSSION}

Inflammatory breast cancer is the primary breast cancer form with the highest aggressiveness $[2,3,66]$. The underlying mechanisms are still unclear but are urgently needed to be deciphered in order to develop novel treatment options [5]. While a common feature of tumors, $\mathrm{ClH}$ is only beginning to be appreciated as an important regulator of cancer progression and metastases. $\mathrm{ClH}$ occurs when cancer cells outgrow the area of sufficient oxygen delivery and subsequent hypoxia-induced tumor angiogenesis leads to vessels with abnormal structures [8]. Such changes have also been demonstrated for IBC tumors $[7,12]$. $\mathrm{ClH}$ is a well-established source for oxidative stress, which can severely impact on gene expression, leading to increased cancer aggressiveness [19]. However, the relevance of CIH for IBC progression and metastases formation is unclear. In this study, we provide insights into the regulation of pro-metastatic gene expression through $\mathrm{IH}$ and oxidative stress in IBC cells, which appears to be mediated mainly by NF-kB (Fig. 8).

We identified that $\mathrm{ClH}$ leads to increased expression of ECM proteins in IBC cells, such as TNC, MMP2, MMP9 and ADAM19, and of proteins involved in inflammatory processes, such as COX-2. TNC, MMP2, MMP9 and COX-2 have previously been shown to highly promote breast cancer metastasis, and to be significantly stronger expressed in IBC tumors than in non-IBC breast cancer tumors $[2,36,66,67]$. Tumor inflammation has also been associated with cancer progression and metastasis formation and COX-2 was identified as a major component of the IBC molecular signature and suggested for targeted therapy for IBC $[2,68]$. Overall, these data demonstrate that $\mathrm{ClH}$ leads to the upregulation of pro-metastatic gene expression in IBC cells, which likely contributes to the aggressive phenotype of IBC.

The transcriptional regulation of the TNC gene is complex and several different stimuli and transcription factors are involved [69]. TNC has previously been 
shown to be regulated by AP-1, NF- $\mathrm{B}$ B and Nrf2 [69-71], and although we observed a ROS-dependent activation of Nrf2, JNK and c-Jun, these factors did not regulate TNC in IBC cells. In our gene array, 33\% of CIH-upregulated genes were identified to carry a putative Nrf2 binding sequence, but we did not observe any prototypical Nrf2 target gene, such as $\mathrm{HO}-1$ or other genes of the cellular antioxidant defense system [23]. Therefore, it seems unlikely that Nrf2 plays a major role in the here observed gene expression and no clear link between Nrf2 activity and IBC has been reported so far.

The effect of oxidative stress on the HIF pathway is controversially discussed in the literature $[8,18,19,24,25,27-29]$. Here, in the CIH experiment, no HIF-1 $\alpha$ stabilization and no prototypical HIF-dependent gene expression pattern was observed. Following a stimulus such as hypoxia, HIF-1 $\alpha$ reaches in most cells its highest protein levels after 6-8 $\mathrm{h}$ and declines subsequently due to negative feedback loops, even during a still continuing HIF-1 $\alpha$ stabilizing stimulus [72-75]. Hence, it is not surprising that no HIF-1 $\alpha$ protein levels and no HIF-dependent gene expression were detected in the $\mathrm{CIH}$ experiments, analyzing the samples $48 \mathrm{~h}$ following the end of the hypoxia period. These results indicate that the observed gene expression was not due to the initial hypoxic stimulus but rather due to the generated oxidative stress, and that this regulation is independent of HIF-1 1 .

The relevance of MAPK signaling and AP-1 activation in IBC is unclear, but overexpression of AP-1 subunits such as c-Jun and MAPK hyperactivation have been suggested $[76,77]$. While ROS-dependent TNC induction was independent of cJun, $83 \%$ of the $\mathrm{ClH}$-upregulated genes could potentially be regulated by AP-1. Therefore, a contribution of $\mathrm{AP}-1$ to $\mathrm{ClH}$-dependent gene regulation in IBC cells cannot be excluded but would need further investigations to determine its relevance. 
We also observed oxidative stress-dependent activation of the NF- $\kappa \mathrm{B}$ signaling cascade at the level of or upstream of $I_{\kappa} \mathrm{B} \alpha$ and TNC, MMP9 and COX-2 were regulated by activation of the NF-кB pathway. TNC has previously been suggested as a putative NF- $\mathrm{KB}$ target gene in IBC $[66,78]$, but although TNC is regulated by this transcription factor in other cell types, to our knowledge an NF-кBdependent TNC regulation had not been shown in IBC cells before. Of note, chronic exposure of SUM149PT cells to IH did not change the ROS production in response to reoxygenation. This indicates that the observed gene regulation following $\mathrm{CIH}$ was either due to an increasing sensitivity of the IBC cells to ROS over the $\mathrm{ClH}$ time course, or that repeated ROS exposures were necessary to sufficiently activate NF$\kappa \mathrm{B}$ for the regulation of gene expression.

The term "inflammatory breast cancer" could suggest an inflammation-driven cancer, but it originated from the clinical appearance of patients $[4,79]$. The role of inflammation in IBC aggressiveness is only beginning to be unraveled. Several studies indicated NF- $\mathrm{KB}$ to be constitutively activated in IBC and to be a major contributor to IBC-specific gene expression and tumorigenesis $[2,66,77,80]$. As

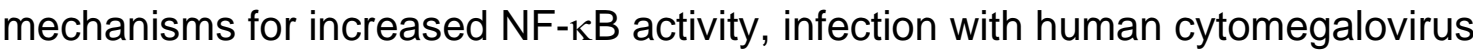
(HCMV), loss of estrogen receptor (ER) and differential cytokine expression has

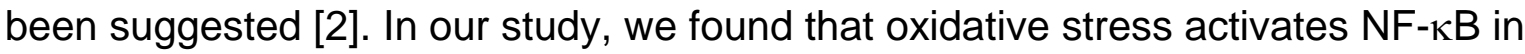
IBC cells and that $64 \%$ of all $\mathrm{ClH}$-upregulated genes can potentially be regulated or

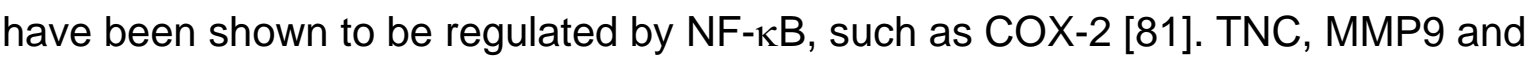

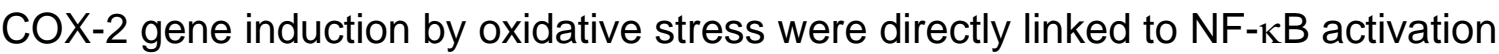
and increased TNC expression was associated with increased p105 expression in breast cancer tissue. Overall, these results demonstrate the importance of NF- $\mathrm{B}$ in pro-metastatic gene regulation in IBC cells in response to intermittent hypoxia. 
Interestingly, TNC can activate toll-like receptor 4, which in turn activates NF-kB, leading to a regulatory loop $[78,82]$. Furthermore, $\mathrm{IH}$ and inflammation can form a vicious circle in vivo, amplifying each other [83]. We therefore hypothesize that $\mathrm{IH}$ and oxidative stress play an important role in the constitutive activation of NF- $\mathrm{kB}$ in IBC, which is facilitated through increased TNC expression.

In summary, $\mathrm{ClH}$ is a possible novel modulator of IBC aggressiveness, increasing pro-metastatic gene expression through activation of NF-kB and maybe other transcription factors. Both $\mathrm{ClH}$ and NF-kB should be further investigated as potential targets for therapy of inflammatory breast cancer. The impact of $\mathrm{ClH}$ should be considered in future studies of IBC tumor material, as $\mathrm{CIH}$ affects gene and protein expression and could lead to differences in expression levels between different biopsy sites. Taking into consideration the crosstalk between the tumor microenvironment and the cancer cells, such as between intermittent hypoxia and IBC cells, might allow us to develop novel approaches for IBC treatment. 


\section{ACKNOWLEDGEMENTS}

We thank the Functional Genomics Center Zurich for performing the Affymetrix Gene array analysis; Rachael Natrajan for providing the SUM149PT cell line and Patrick Spielmann for excellent technical assistance.

This project was supported by grants from the Vontobel-Stiftung (to C.L.), from the KFSP Tumor Oxygenation of the University of Zurich (to R.H.W.), from the Swiss National Science Foundation (SNSF, grant number 31003A_165679, to R.H.W.) and from the University Research Priority Program (URPP) "Integrative Human Physiology" (to E.R.). The funding sources had no role in the design of the study, writing of the manuscript or collection, analysis and data interpretation.

\section{AUTHOR DISCLOSURE STATEMENT}

The authors declare no conflicts of interest. 


\section{REFERENCES}

[1] S. Dawood, S.D. Merajver, P. Viens, P.B. Vermeulen, S.M. Swain, T.A. Buchholz, L.Y. Dirix, P.H. Levine, A. Lucci, S. Krishnamurthy, F.M. Robertson, W.A. Woodward, W.T. Yang, N.T. Ueno, M. Cristofanilli, International expert panel on inflammatory breast cancer: consensus statement for standardized diagnosis and treatment, Ann Oncol 22(3) (2011) 515-23.

[2] T.M. Fouad, T. Kogawa, J.M. Reuben, N.T. Ueno, The role of inflammation in inflammatory breast cancer, Adv Exp Med Biol 816 (2014) 53-73.

[3] M.M. Mohamed, D. Al-Raawi, S.F. Sabet, M. El-Shinawi, Inflammatory breast cancer: New factors contribute to disease etiology: A review, J Adv Res 5(5) (2014) $525-36$.

[4] M. Cariati, T.M. Bennett-Britton, S.E. Pinder, A.D. Purushotham, "Inflammatory" breast cancer, Surg Oncol 14(3) (2005) 133-43.

[5] F. Bertucci, P. Finetti, P. Vermeulen, P. Van Dam, L. Dirix, D. Birnbaum, P. Viens, $S$. Van Laere, Genomic profiling of inflammatory breast cancer: a review, Breast 23(5) (2014) 538-45.

[6] N. Barnabas, D. Cohen, Phenotypic and Molecular Characterization of MCF10DCIS and SUM Breast Cancer Cell Lines, Int J Breast Cancer 2013 (2013) 872743 .

[7] D. Liao, R.S. Johnson, Hypoxia: a key regulator of angiogenesis in cancer, Cancer Metastasis Rev 26(2) (2007) 281-90.

[8] M.W. Dewhirst, Y. Cao, B. Moeller, Cycling hypoxia and free radicals regulate angiogenesis and radiotherapy response, Nat Rev Cancer 8(6) (2008) 425-37.

[9] C. Michiels, C. Tellier, O. Feron, Cycling hypoxia: A key feature of the tumor microenvironment, Biochim Biophys Acta (2016).

[10] D.J. van Uden, H.W. van Laarhoven, A.H. Westenberg, J.H. de Wilt, C.F. Blanken-Peeters, Inflammatory breast cancer: an overview, Crit Rev Oncol Hematol 93(2) (2015) 116-26.

[11] N.J. McCarthy, X. Yang, I.R. Linnoila, M.J. Merino, S.M. Hewitt, A.L. Parr, S. Paik, S.M. Steinberg, D.P. Hartmann, N. Mourali, P.H. Levine, S.M. Swain, Microvessel density, expression of estrogen receptor alpha, MIB-1, p53, and c-erbB2 in inflammatory breast cancer, Clin Cancer Res 8(12) (2002) 3857-62.

[12] P.B. Vermeulen, K.L. van Golen, L.Y. Dirix, Angiogenesis, lymphangiogenesis, growth pattern, and tumor emboli in inflammatory breast cancer: a review of the current knowledge, Cancer 116(11 Suppl) (2010) 2748-54.

[13] E.K. Rofstad, J.V. Gaustad, T.A. Egeland, B. Mathiesen, K. Galappathi, Tumors exposed to acute cyclic hypoxic stress show enhanced angiogenesis, perfusion and metastatic dissemination, Int J Cancer 127(7) (2010) 1535-46. 
[14] R.A. Cairns, R.P. Hill, Acute hypoxia enhances spontaneous lymph node metastasis in an orthotopic murine model of human cervical carcinoma, Cancer Res 64(6) (2004) 2054-61.

[15] R.A. Cairns, T. Kalliomaki, R.P. Hill, Acute (cyclic) hypoxia enhances spontaneous metastasis of KHT murine tumors., Cancer Res 61(24) (2001) 89038908.

[16] S.R. McKeown, Defining normoxia, physoxia and hypoxia in tumoursimplications for treatment response, $\mathrm{Br} \mathrm{J}$ Radiol 87(1035) (2014) 20130676.

[17] R.H. Wenger, V. Kurtcuoglu, C.C. Scholz, H.H. Marti, D. Hoogewijs, Frequently asked questions in hypoxia research, Hypoxia 3 (2015) 35-43.

[18] J. Nanduri, G. Yuan, G.K. Kumar, G.L. Semenza, N.R. Prabhakar, Transcriptional responses to intermittent hypoxia, Respir Physiol Neurobiol 164(1-2) (2008) 277-81.

[19] S. Toffoli, C. Michiels, Intermittent hypoxia is a key regulator of cancer cell and endothelial cell interplay in tumours, Febs J 275(12) (2008) 2991-3002.

[20] Y. Mikhed, A. Gorlach, U.G. Knaus, A. Daiber, Redox regulation of genome stability by effects on gene expression, epigenetic pathways and DNA damage/repair, Redox Biol 5 (2015) 275-89.

[21] J. Zhang, X. Wang, V. Vikash, Q. Ye, D. Wu, Y. Liu, W. Dong, ROS and ROSMediated Cellular Signaling, Oxid Med Cell Longev 2016 (2016) 4350965.

[22] S. Ryan, C.T. Taylor, W.T. McNicholas, Selective activation of inflammatory pathways by intermittent hypoxia in obstructive sleep apnea syndrome, Circulation 112(17) (2005) 2660-7.

[23] A.L. Furfaro, N. Traverso, C. Domenicotti, S. Piras, L. Moretta, U.M. Marinari, M.A. Pronzato, M. Nitti, The Nrf2/HO-1 Axis in Cancer Cell Growth and Chemoresistance, Oxid Med Cell Longev 2016 (2016) 1958174.

[24] G.B. Waypa, K.A. Smith, P.T. Schumacker, O2 sensing, mitochondria and ROS signaling: The fog is lifting, Mol Aspects Med 47-48 (2016) 76-89.

[25] T. Hagen, C.T. Taylor, F. Lam, S. Moncada, Redistribution of intracellular oxygen in hypoxia by nitric oxide: effect on HIF1alpha, Science 302(5652) (2003) 1975-8.

[26] Y.L. Chua, E. Dufour, E.P. Dassa, P. Rustin, H.T. Jacobs, C.T. Taylor, T. Hagen, Stabilization of hypoxia-inducible factor-1alpha protein in hypoxia occurs independently of mitochondrial reactive oxygen species production, The Journal of biological chemistry 285(41) (2010) 31277-84.

[27] K.J. Nytko, P. Spielmann, G. Camenisch, R.H. Wenger, D.P. Stiehl, Regulated function of the prolyl-4-hydroxylase domain (PHD) oxygen sensor proteins, Antioxid Redox Signal 9(9) (2007) 1329-38. 
[28] N. Masson, R.S. Singleton, R. Sekirnik, D.C. Trudgian, L.J. Ambrose, M.X. Miranda, Y.M. Tian, B.M. Kessler, C.J. Schofield, P.J. Ratcliffe, The FIH hydroxylase is a cellular peroxide sensor that modulates HIF transcriptional activity, EMBO Rep 13(3) (2012) 251-7.

[29] K.J. Nytko, N. Maeda, P. Schlafli, P. Spielmann, R.H. Wenger, D.P. Stiehl, Vitamin $C$ is dispensable for oxygen sensing in vivo, Blood 117(20) (2011) 5485-93.

[30] E. Shaulian, AP-1--The Jun proteins: Oncogenes or tumor suppressors in disguise?, Cell Signal 22(6) (2010) 894-9.

[31] S. Reuter, S.C. Gupta, M.M. Chaturvedi, B.B. Aggarwal, Oxidative stress, inflammation, and cancer: how are they linked?, Free Radic Biol Med 49(11) (2010) 1603-16.

[32] C.C. Scholz, C.T. Taylor, Hydroxylase-dependent regulation of the NF-kappaB pathway, Biol Chem 394(4) (2013) 479-93.

[33] K. Muller-Edenborn, K. Leger, J.F. Glaus Garzon, C. Oertli, A. Mirsaidi, P.J. Richards, H. Rehrauer, P. Spielmann, D. Hoogewijs, L. Borsig, M.O. Hottiger, R.H. Wenger, Hypoxia attenuates the proinflammatory response in colon cancer cells by regulating IkappaB, Oncotarget 6(24) (2015) 20288-301.

[34] X. Dolcet, D. Llobet, J. Pallares, X. Matias-Guiu, NF-kB in development and progression of human cancer, Virchows Arch 446(5) (2005) 475-82.

[35] C.H. Lee, Y.T. Jeon, S.H. Kim, Y.S. Song, NF-kappaB as a potential molecular target for cancer therapy, Biofactors 29(1) (2007) 19-35.

[36] J. Insua-Rodriguez, T. Oskarsson, The extracellular matrix in breast cancer, Adv Drug Deliv Rev 97 (2016) 41-55.

[37] B. Qi, R.G. Newcomer, Q.X. Sang, ADAM19/adamalysin 19 structure, function, and role as a putative target in tumors and inflammatory diseases, Current pharmaceutical design 15(20) (2009) 2336-48.

[38] G. Orend, R. Chiquet-Ehrismann, Tenascin-C induced signaling in cancer., Cancer Lett 244(2) (2006) 143-163.

[39] T. Oskarsson, S. Acharyya, X.H. Zhang, S. Vanharanta, S.F. Tavazoie, P.G. Morris, R.J. Downey, K. Manova-Todorova, E. Brogi, J. Massague, Breast cancer cells produce tenascin $\mathrm{C}$ as a metastatic niche component to colonize the lungs, Nat Med 17(7) (2011) 867-74.

[40] A. Schörg, S. Santambrogio, J.L. Platt, J. Schödel, M.T. Lindenmeyer, C.D. Cohen, K. Schrödter, D.R. Mole, R.H. Wenger, D. Hoogewijs, Destruction of a distal hypoxia response element abolishes trans-activation of the PAG1 gene mediated by HIF-independent chromatin looping, Nucleic Acids Res 43(12) (2015) 5810-23.

[41] D.H. Larsen, F. Hari, J.A. Clapperton, M. Gwerder, K. Gutsche, M. Altmeyer, S. Jungmichel, L.I. Toledo, D. Fink, M.B. Rask, M. Grofte, C. Lukas, M.L. Nielsen, S.J. 
Smerdon, J. Lukas, M. Stucki, The NBS1-Treacle complex controls ribosomal RNA transcription in response to DNA damage, Nat Cell Biol 16(8) (2014) 792-803.

[42] J.H. Fuady, K. Gutsche, S. Santambrogio, Z. Varga, D. Hoogewijs, R.H. Wenger, Estrogen-dependent downregulation of hypoxia-inducible factor (HIF)-2alpha in invasive breast cancer cells, Oncotarget (2016).

[43] A. Naba, K.R. Clauser, H. Ding, C.A. Whittaker, S.A. Carr, R.O. Hynes, The extracellular matrix: Tools and insights for the "omics" era, Matrix Biol 49 (2016) 1024.

[44] A.T. Kwon, D.J. Arenillas, R. Worsley Hunt, W.W. Wasserman, oPOSSUM-3: advanced analysis of regulatory motif over-representation across genes or ChIP-Seq datasets, G3 (Bethesda) 2(9) (2012) 987-1002.

[45] S.J. Ho Sui, D.L. Fulton, D.J. Arenillas, A.T. Kwon, W.W. Wasserman, oPOSSUM: integrated tools for analysis of regulatory motif over-representation, Nucleic Acids Res 35(Web Server issue) (2007) W245-52.

[46] S.J. Ho Sui, J.R. Mortimer, D.J. Arenillas, J. Brumm, C.J. Walsh, B.P. Kennedy, W.W. Wasserman, oPOSSUM: identification of over-represented transcription factor binding sites in co-expressed genes, Nucleic Acids Res 33(10) (2005) 3154-64.

[47] E. Portales-Casamar, S. Thongjuea, A.T. Kwon, D. Arenillas, X. Zhao, E. Valen, D. Yusuf, B. Lenhard, W.W. Wasserman, A. Sandelin, JASPAR 2010: the greatly expanded open-access database of transcription factor binding profiles, Nucleic Acids Res 38(Database issue) (2010) D105-10.

[48] W.J. Kent, C.W. Sugnet, T.S. Furey, K.M. Roskin, T.H. Pringle, A.M. Zahler, D. Haussler, The human genome browser at UCSC, Genome Res 12(6) (2002) 9961006.

[49] M. Pachkov, I. Erb, N. Molina, E. van Nimwegen, SwissRegulon: a database of genome-wide annotations of regulatory sites, Nucleic Acids Res 35(Database issue) (2007) D127-31.

[50] M.B. Kannan, I. Dodard-Friedman, V. Blank, Stringent Control of NFE2L3 (Nuclear Factor, Erythroid 2-Like 3; NRF3) Protein Degradation by FBW7 (F-box/WD Repeat-containing Protein 7) and Glycogen Synthase Kinase 3 (GSK3), J Biol Chem 290(43) (2015) 26292-302.

[51] N.D. Camp, R.G. James, D.W. Dawson, F. Yan, J.M. Davison, S.A. Houck, X. Tang, N. Zheng, M.B. Major, R.T. Moon, Wilms Tumor Gene on X Chromosome (WTX) Inhibits Degradation of NRF2 Protein through Competitive Binding to KEAP1 Protein, Journal of Biological Chemistry 287(9) (2012) 6539-6550.

[52] S. Sun, J. Elwood, W.C. Greene, Both amino- and carboxyl-terminal sequences within I kappa B alpha regulate its inducible degradation, Mol Cell Biol 16(3) (1996) 1058-65. 
[53] H. Wang, J.A. Joseph, Quantifying cellular oxidative stress by dichlorofluorescein assay using microplate reader., Free radical biology \&amp; medicine 27(5-6) (1999) 612-616.

[54] K. Sankaranarayanan, A.K. Jaiswal, Nrf3 negatively regulates antioxidantresponse element-mediated expression and antioxidant induction of NAD(P)H:quinone oxidoreductase1 gene, J Biol Chem 279(49) (2004) 50810-7.

[55] S.B. Ahmed, S.A. Prigent, A nuclear export signal and oxidative stress regulate ShcD subcellular localisation: a potential role for $\mathrm{ShcD}$ in the nucleus, Cell Signal 26(1) (2014) 32-40.

[56] E. Fagiani, G. Giardina, L. Luzi, M. Cesaroni, M. Quarto, M. Capra, G. Germano, M. Bono, M. Capillo, P. Pelicci, L. Lanfrancone, RaLP, a new member of the Src homology and collagen family, regulates cell migration and tumor growth of metastatic melanomas, Cancer Res 67(7) (2007) 3064-73.

[57] C.B. Tempfer, L.A. Hefler, C. Schneeberger, J.C. Huber, How valid is single nucleotide polymorphism (SNP) diagnosis for the individual risk assessment of breast cancer?, Gynecol Endocrinol 22(3) (2006) 155-9.

[58] G.L. Semenza, N.R. Prabhakar, HIF-1-dependent respiratory, cardiovascular, and redox responses to chronic intermittent hypoxia, Antioxid Redox Signal 9(9) (2007) 1391-6.

[59] R. Pinkus, L.M. Weiner, V. Daniel, Role of oxidants and antioxidants in the induction of AP-1, NF-kappaB, and glutathione S-transferase gene expression, J Biol Chem 271(23) (1996) 13422-9.

[60] M. Ishikawa, S. Numazawa, T. Yoshida, Redox regulation of the transcriptional repressor Bach1, Free Radic Biol Med 38(10) (2005) 1344-52.

[61] G. Chevillard, V. Blank, NFE2L3 (NRF3): the Cinderella of the Cap'n'Collar transcription factors, Cell Mol Life Sci 68(20) (2011) 3337-48.

[62] F. Hong, M.L. Freeman, D.C. Liebler, Identification of sensor cysteines in human Keap1 modified by the cancer chemopreventive agent sulforaphane, Chem Res Toxicol 18(12) (2005) 1917-26.

[63] M.S. Brennan, M.F. Matos, B. Li, X. Hronowski, B. Gao, P. Juhasz, K.J. Rhodes, R.H. Scannevin, Dimethyl fumarate and monoethyl fumarate exhibit differential effects on KEAP1, NRF2 activation, and glutathione depletion in vitro, PLoS One 10(3) (2015) e0120254.

[64] S. Vallabhapurapu, M. Karin, Regulation and function of NF-kappaB transcription factors in the immune system, Annu Rev Immunol 27 (2009) 693-733.

[65] C.C. Scholz, M.A. Cavadas, M.M. Tambuwala, E. Hams, J. Rodriguez, A. von Kriegsheim, P. Cotter, U. Bruning, P.G. Fallon, A. Cheong, E.P. Cummins, C.T. Taylor, Regulation of IL-1beta-induced NF-kappaB by hydroxylases links key hypoxic and inflammatory signaling pathways, Proc Natl Acad Sci U S A 110(46) (2013) 18490-5. 
[66] F. Lerebours, S. Vacher, C. Andrieu, M. Espie, M. Marty, R. Lidereau, I. Bieche, NF-kappa B genes have a major role in inflammatory breast cancer, BMC Cancer 8 (2008) 41.

[67] D. Al-Raawi, H. Abu-El-Zahab, M. El-Shinawi, M.M. Mohamed, Membrane type1 matrix metalloproteinase (MT1-MMP) correlates with the expression and activation of matrix metalloproteinase-2 (MMP-2) in inflammatory breast cancer, Int $\mathrm{J}$ Clin Exp Med 4(4) (2011) 265-75.

[68] A. Mantovani, P. Allavena, A. Sica, F. Balkwill, Cancer-related inflammation, Nature 454(7203) (2008) 436-44.

[69] S.P. Giblin, K.S. Midwood, Tenascin-C: Form versus function, Cell Adh Migr 9(12) (2015) 48-82.

[70] S. Eba, Y. Hoshikawa, T. Moriguchi, Y. Mitsuishi, H. Satoh, K. Ishida, T. Watanabe, T. Shimizu, H. Shimokawa, Y. Okada, M. Yamamoto, T. Kondo, The nuclear factor erythroid 2-related factor 2 activator oltipraz attenuates chronic hypoxia-induced cardiopulmonary alterations in mice, Am J Respir Cell Mol Biol 49(2) (2013) 324-33.

[71] F. Chiovaro, R. Chiquet-Ehrismann, M. Chiquet, Transcriptional regulation of tenascin genes, Cell Adh Migr 9(1-2) (2015) 34-47.

[72] D.P. Stiehl, R. Wirthner, J. Koditz, P. Spielmann, G. Camenisch, R.H. Wenger, Increased prolyl 4-hydroxylase domain proteins compensate for decreased oxygen levels. Evidence for an autoregulatory oxygen-sensing system, The Journal of biological chemistry 281(33) (2006) 23482-91.

[73] U. Bruning, L. Cerone, Z. Neufeld, S.F. Fitzpatrick, A. Cheong, C.C. Scholz, D.A. Simpson, M.O. Leonard, M.M. Tambuwala, E.P. Cummins, C.T. Taylor, MicroRNA155 promotes resolution of hypoxia-inducible factor 1alpha activity during prolonged hypoxia, Molecular and cellular biology 31(19) (2011) 4087-96.

[74] L.K. Nguyen, M.A. Cavadas, C.C. Scholz, S.F. Fitzpatrick, U. Bruning, E.P. Cummins, M.M. Tambuwala, M.C. Manresa, B.N. Kholodenko, C.T. Taylor, A. Cheong, A dynamic model of the hypoxia-inducible factor 1-alpha (HIF-1alpha) network, Journal of cell science (2013).

[75] M.A. Cavadas, M. Mesnieres, B. Crifo, M.C. Manresa, A.C. Selfridge, C.C. Scholz, E.P. Cummins, A. Cheong, C.T. Taylor, REST mediates resolution of HIFdependent gene expression in prolonged hypoxia, Sci Rep 5 (2015) 17851.

[76] I. Bieche, F. Lerebours, S. Tozlu, M. Espie, M. Marty, R. Lidereau, Molecular profiling of inflammatory breast cancer: identification of a poor-prognosis gene expression signature, Clin Cancer Res 10(20) (2004) 6789-95.

[77] S.J. Van Laere, I. Van der Auwera, G.G. Van den Eynden, P. van Dam, E.A. Van Marck, P.B. Vermeulen, L.Y. Dirix, NF-kappaB activation in inflammatory breast cancer is associated with oestrogen receptor downregulation, secondary to EGFR and/or ErbB2 overexpression and MAPK hyperactivation, Br J Cancer 97(5) (2007) 659-69. 
[78] F.G. Goh, A.M. Piccinini, T. Krausgruber, I.A. Udalova, K.S. Midwood, Transcriptional regulation of the endogenous danger signal tenascin-C: a novel autocrine loop in inflammation, J Immunol 184(5) (2010) 2655-62.

[79] W.A. Woodward, Inflammatory breast cancer: unique biological and therapeutic considerations, Lancet Oncol 16(15) (2015) e568-76.

[80] S.J. Van Laere, I. Van der Auwera, G.G. Van den Eynden, H.J. Elst, J. Weyler, A.L. Harris, P. van Dam, E.A. Van Marck, P.B. Vermeulen, L.Y. Dirix, Nuclear factorkappaB signature of inflammatory breast cancer by cDNA microarray validated by quantitative real-time reverse transcription-PCR, immunohistochemistry, and nuclear factor-kappaB DNA-binding, Clin Cancer Res 12(11 Pt 1) (2006) 3249-56.

[81] S.F. Fitzpatrick, M.M. Tambuwala, U. Bruning, B. Schaible, C.C. Scholz, A. Byrne, A. O'Connor, W.M. Gallagher, C.R. Lenihan, J.F. Garvey, K. Howell, P.G. Fallon, E.P. Cummins, C.T. Taylor, An intact canonical NF-kappaB pathway is required for inflammatory gene expression in response to hypoxia, Journal of immunology 186(2) (2011) 1091-6.

[82] K. Midwood, S. Sacre, A.M. Piccinini, J. Inglis, A. Trebaul, E. Chan, S. Drexler, N. Sofat, M. Kashiwagi, G. Orend, F. Brennan, B. Foxwell, Tenascin-C is an endogenous activator of Toll-like receptor 4 that is essential for maintaining inflammation in arthritic joint disease, Nat Med 15(7) (2009) 774-80.

[83] C. Tellier, D. Desmet, L. Petit, L. Finet, C. Graux, M. Raes, O. Feron, C. Michiels, Cycling hypoxia induces a specific amplified inflammatory phenotype in endothelial cells and enhances tumor-promoting inflammation in vivo, Neoplasia 17(1) (2015) 66-78. 


\section{FIGURE LEGENDS}

Fig. 1: Genes regulated by chronic intermittent hypoxia $(\mathrm{CIH})$ in inflammatory breast cancer cells. (A) Experimental scheme of the $\mathrm{ClH}$ exposure regime, indicating the duration of exposure to hypoxia and normoxia, and the time points of sample collection. (B) Enrichment analysis of upregulated genes using MetaCore software to rank the most relevant cellular processes.

\section{Fig. 2: Gene array validation reveals three distinct groups of genes regulated} by $\mathrm{ClH}$. (A) Validation of gene array results for selected candidate genes in SUM149PT cells by RT-qPCR. (B) Heatmap showing the mRNA induction factors depicted in (A) following hypoxia, reoxygenation or $\mathrm{ClH}$. (C) Immunoblot analysis of TNC protein levels in response to hypoxia, reoxygenation or CIH. (D) Quantification of TNC protein levels following hypoxia, reoxygenation or $\mathrm{ClH}$. Hyp = hypoxia, Reox $=$ reoxygenation; ${ }^{*}, p<0.05 ;{ }^{* *}, p<0.01 ;{ }^{* * *}, p<0.001$ (Student's t-test).

Fig. 3: Regulation of $T N C$ gene expression by oxidative stress. DCF assays to quantify the generation of intracellular ROS levels by (A) reoxygenation (following 24 h $0.2 \% \mathrm{O}_{2}$ ), (B) $100 \mu \mathrm{M} \mathrm{H}_{2} \mathrm{O}_{2}$ or (C) $30 \mu \mathrm{M} \mathrm{tBHQ}$ over $4 \mathrm{~h}$. RT-qPCR analysis of TNC mRNA induction in response to (D) reoxygenation (following $24 \mathrm{~h} 0.2 \% \mathrm{O}_{2}$ ), (E) 100 $\mu \mathrm{M} \mathrm{H}_{2} \mathrm{O}_{2}$ or $(\mathbf{F}) 30 \mu \mathrm{M} \mathrm{tBHQ}$ over the indicated time course. TNC immunoblot analysis and quantification of relative protein levels in response to $(G)$ reoxygenation (following $24 \mathrm{~h} 0.2 \% \mathrm{O}_{2}$ ), (H) $100 \mu \mathrm{M} \mathrm{H}_{2} \mathrm{O}_{2}$ or (I) $30 \mu \mathrm{M} \mathrm{tBHQ}$ over the indicated time course. (J) Determination of secreted TNC protein levels in response to $30 \mu \mathrm{M} \mathrm{tBHQ}$ over 24 hours by ELISA. Cell culture supernatants were used from samples of the experiment shown in Fig.4B. ${ }^{\star}, p<0.05 ;{ }^{* \star}, p<0.01 ;{ }^{* \star}, p<0.001$ (one-way ANOVA 
followed by Tukey test for (D, G); Student's t-test (J); two-way ANOVA followed by Bonferroni posttest for all other statistical analyses).

\section{Fig. 4: Effects of antioxidants on tBHQ-mediated TNC induction. (A) DCF} analysis of tBHQ treatment $(30 \mu \mathrm{M})$ alone or following $1 \mathrm{~h}$ pre-treatment with $3 \mathrm{mM}$ NAC. (B) Analysis and quantification of relative TNC protein levels in SUM149PT cells in response to $30 \mu \mathrm{M} \mathrm{tBHQ}$ alone or following $1 \mathrm{~h}$ pre-treatment with $3 \mathrm{mM}$ or 20 mM NAC. Quantified values were normalized to $\beta$-actin loading control and to the starting time point. n.s., not significant; ${ }^{* *}, p<0.01 ;{ }^{* * *}, p<0.001$ (Two-way ANOVA followed by Bonferroni posttest was applied for comparison of tBHQ treatment alone with the combinatorial treatment of $\mathrm{BH} \mathrm{BQ}$ and NAC in (A); one-way ANOVA followed by Tukey test in (B)).

Fig. 5: Role of Nrf2 and Nrf3 in oxidative stress-dependent TNC regulation. (A) UCSC-integrated ENCODE data proximal to the transcriptional start site of the TNC gene. The transcription factor ChIP-sequencing track shows regions of transcription factor binding derived from ChIP-seq experiments performed by the ENCODE project. The intensity of the grey shading is proportional to the signal strength observed in any cell line contributing to the respective cluster. Enrichment levels of histone marks (H3K4Me1, H3K4Me3, H3K27Ac) were determined by ChIP-seq and indicate regions of active enhancers (H3K4Me1, H3K27Ac) or active promoters (H3K4Me3). DNase hypersensitive areas reflect regulatory regions. Further relevant TFBS found in JASPAR and from published results were added in rectangles [71]. A circle shows relevant, additional TFBS found in the Swissregulon database. JUN, cJun; ARE, antioxidant response element, targeted by Nrf2 and Nrf3. (B) Nrf2 or Nrf3 
alone or Nrf2/Nrf3 in combination were knocked down for $48 \mathrm{~h}$ followed by treatment with $30 \mu \mathrm{M} \mathrm{tBHQ}$ or solvent control (ethanol) for the indicated time points. TNC and

(C) HO-1 mRNA levels were determined by RT-qPCR and normalized to $0 \mathrm{~h}$ siCtrl.

(D) Cells were treated with $10 \mu \mathrm{M}$ SFN or solvent control (DMSO) and TNC and HO1 mRNA levels were determined by RT-qPCR. (E) TNC and HO-1 mRNA levels were determined by RT-qPCR following treatment with $40 \mu \mathrm{M}$ DMF or solvent control (DMSO). n.s., not significant; ${ }^{*}, p<0.05 ;{ }^{* *}, p<0.01 ;{ }^{* * *}, p<0.001$ (two-way ANOVA followed by Bonferroni posttest).

Fig. 6: Role of JNK and c-Jun activity in oxidative stress-dependent TNC regulation. (A) Immunoblot analysis of total C-Jun and phosphorylated c-Jun protein after treatment with $30 \mu \mathrm{M} \mathrm{tBHQ}$ or solvent control (ethanol) for the indicated time points. (B) SUM149PT cells were pre-treated for $1 \mathrm{~h}$ with different concentrations of the JNK inhibitor SP600125 (SP6) followed by a $9 \mathrm{~h}$ treatment with $30 \mu \mathrm{M} \mathrm{tBHQ}$ or solvent control (ethanol). Total c-Jun and phosphorylated c-Jun protein was detected by immunoblotting. (C) Immunoblot analysis and quantification of relative TNC protein levels in response to $30 \mu \mathrm{M} \mathrm{tBHQ}$ with or without $1 \mathrm{~h}$ pre-treatment with different concentrations of the JNK inhibitor SP600125 for the indicated time points. (D) Immunoblot analysis and quantification of relative of TNC protein levels after knockdown of c-Jun for $48 \mathrm{~h}$ and followed by treatment with $30 \mu \mathrm{M} \mathrm{tBHQ}$ or solvent control (ethanol) for the indicated time points. n.s., not significant; ${ }^{* \star}, p<0.01 ;{ }^{* * *}$, $p<0.001$ (one-way ANOVA followed by Tukey test).

Fig. 7: Role of NF-kB in oxidative stress-dependent TNC regulation. (A) Immunoblot analysis of $\mathrm{I}_{\kappa} \mathrm{B} \alpha$ protein levels following treatment with $30 \mu \mathrm{M} \mathrm{tBHQ}$ or 
solvent control (ethanol) for the indicated time points. (B) $I_{\kappa} B \alpha$ protein levels were analysed by immunoblotting following $1 \mathrm{~h}$ pre-treatment with different concentrations of the IKB kinase (IKK) inhibitor BAY 11-7082 (BAY) and subsequent addition of 30 $\mu \mathrm{M} \mathrm{tBHQ}$ or solvent control (ethanol) for $9 \mathrm{~h}$. (C) SUM149PT cells were pretreated for $1 \mathrm{~h}$ with $12.5 \mu \mathrm{M}$ BAY 11-7082 followed by $30 \mu \mathrm{M} \mathrm{tBHQ}$ or solvent control (ethanol) for indicated time periods. TNC, MMP9 and COX-2 protein levels were analysed by immunoblotting and TNC levels were quantified. (D) Following transient overexpression of $I_{\kappa} B \alpha$ for $24 \mathrm{~h}$, cells were treated with $30 \mu \mathrm{M} t \mathrm{BHQ}$ or solvent control (ethanol) for the indicated time periods and TNC, MMP9 and COX-2 protein levels were analyzed by immunoblotting. For the shown MMP9 immunoblot a previously cut membrane was used in an otherwise identical single experiment. (E) SUM149PT cells were treated with $2 \mathrm{ng} / \mathrm{ml} \mathrm{IL-1 \beta}$ or solvent control $(0.1 \% \mathrm{BSA}$ in PBS) for the indicated time course and $\mathrm{I} \kappa \mathrm{B} \alpha, \mathrm{TNC}, \mathrm{MMP} 9$ and COX-2 protein levels were analyzed by immunoblotting. (F) Analysis of NF- $\mathrm{KB}$ binding sites in all $\mathrm{ClH}$ upregulated genes, observed in the gene array shown in Supplementary Table S1. The graph depicts the combined results of TFBS identification using the web-based software oPOSSUM and MetaCore. oPOSSUM and MetaCore identified TFBS profiles based on JASPAR and published results, respectively. n.s., not significant; ${ }^{* * *}, p<0.001$ (one-way ANOVA followed by Tukey test).

Fig. 8: Proposed model of the molecular mechanisms by which intermittent hypoxia mediates pro-metastatic gene expression via activation of NF-kB in inflammatory breast cancer cells. Intermittent hypoxia upregulates pro-metastatic genes in inflammatory breast cancer cells through activation of the transcription factor NF-kB. 
Sample collection $\frac{\text { Cycle } 1}{1^{\text {st }} \text { Hypoxia } 1^{\text {st }} \text { Reoxy }}$

$\downarrow$

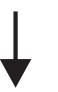

$\longdiv { 1 4 x }$

Intermittent hypoxia
$\mathrm{CIH}$

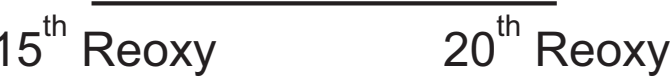

$5 x$

Normoxia Hypoxia Normoxia Hypoxia Normoxia Hypoxia Normoxia

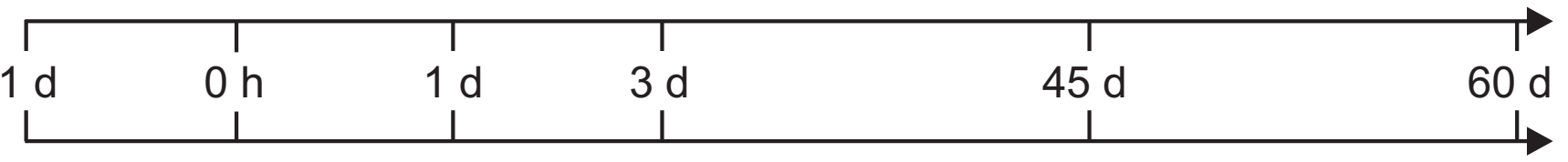

Normoxic control

\begin{tabular}{|l|l|l|l|l|l|l|}
\hline Normoxia & Normoxia & Normoxia & Normoxia & Normoxia & Normoxia & Normoxia \\
\hline
\end{tabular}

- $\log (\mathrm{pValue})$

$\begin{array}{llll}1 & 2 & 3 & 4 \\ 1 & 1 & 1 & 1\end{array}$

1. Cell adhesion_Cell-matrix interactions

2. Proteolysis_Connective tissue degradation

3. Proteolysis_ECM remodeling

4. Inflammation_IL-10 anti-inflammatory response

5. Inflammation_MIF signaling

6. Inflammation_Innate inflammatory response

7. Inflammation_Kallikrein-kinin system

8. Blood coagulation

9. Inflammation_Histamine signaling

10. Inflammation_Amphoterin signaling 
Figure 4

A

ô

250
200
150
100
40
20
0
-20

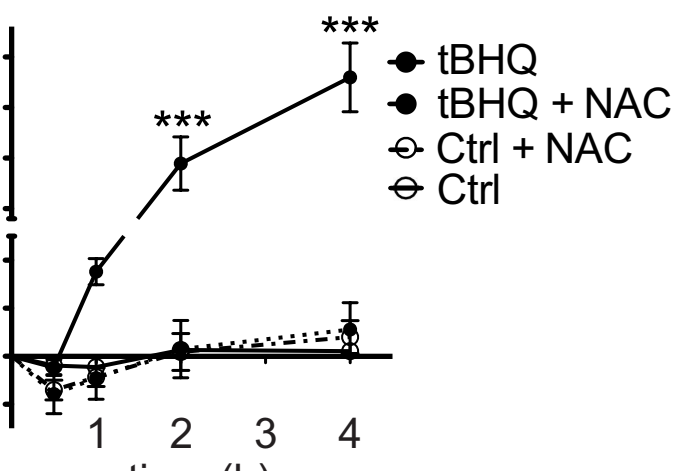

B

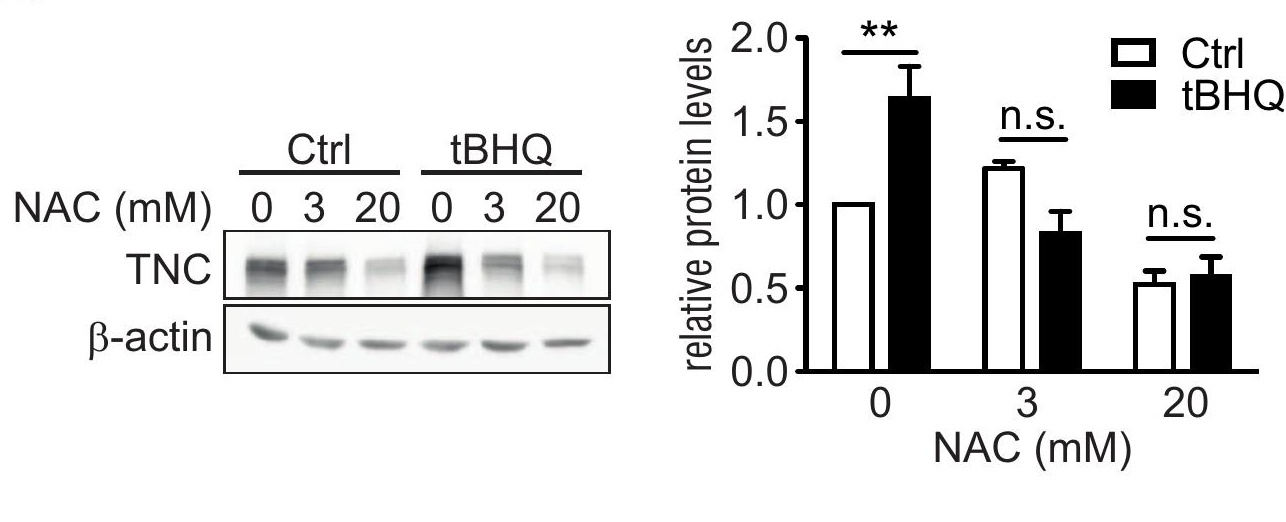


Figure 5
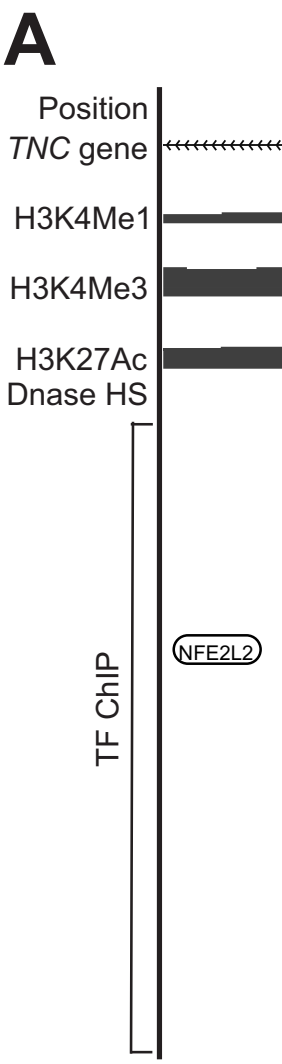

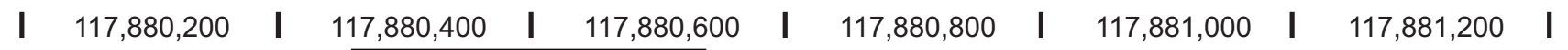

B

TNC

n.s.

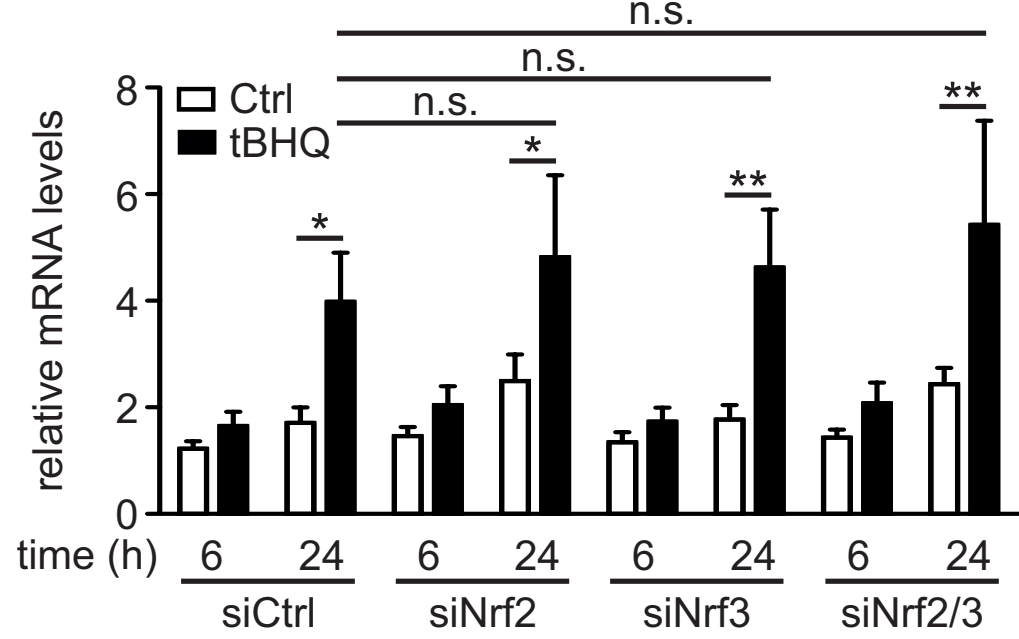

D

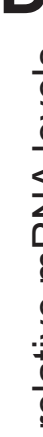

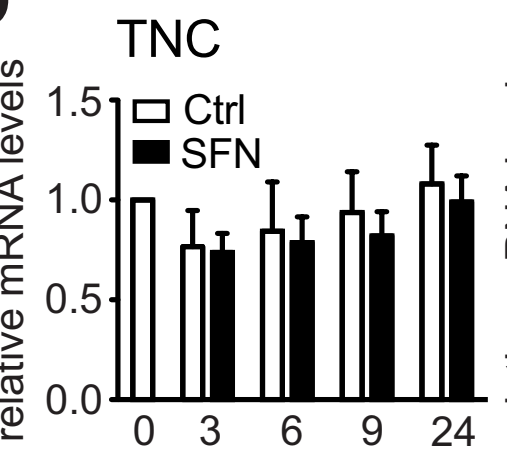

time (h)

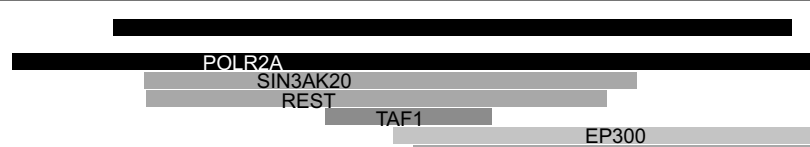

RBBP5

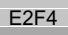

NG-KB

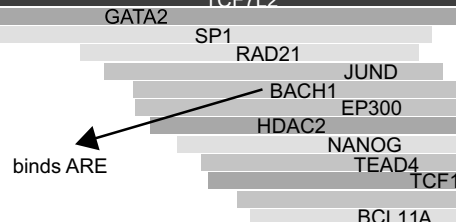

BCL11A
FOSL2
JUND
JUN

JUN
STAT
MAX

MAX
POLR2A

MYAP
TFY1 YY1
RAD21
TFAP2

FOS

C $\mathrm{HO}_{-1}$

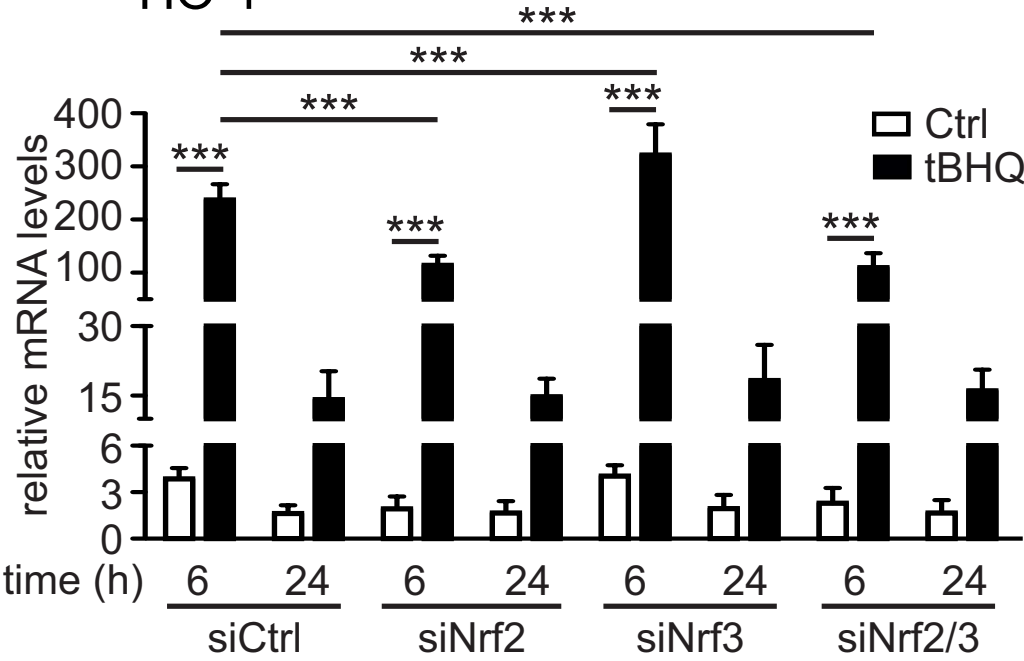

E

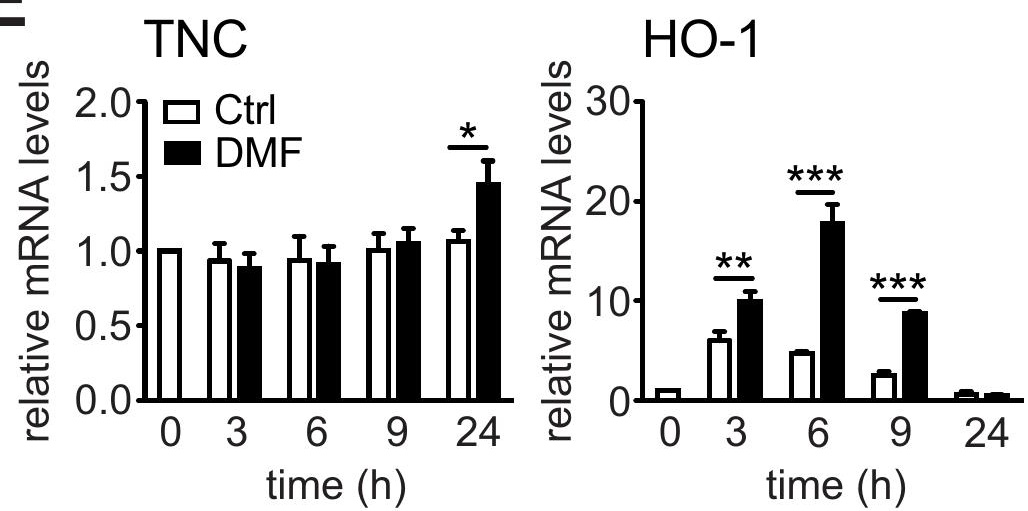


A

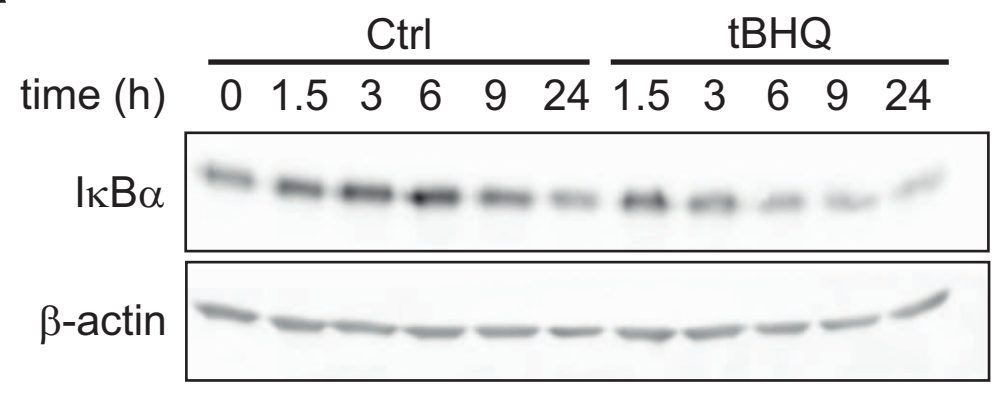

C

$\begin{aligned} \mathrm{BAY}(\mu \mathrm{M}) & \frac{9 \mathrm{~h}}{\mathrm{t}} \frac{0}{\mathrm{tBHQ}} \frac{12.5}{-} \frac{0}{-}+\frac{12.5}{-}+\frac{1}{-}+\end{aligned}$
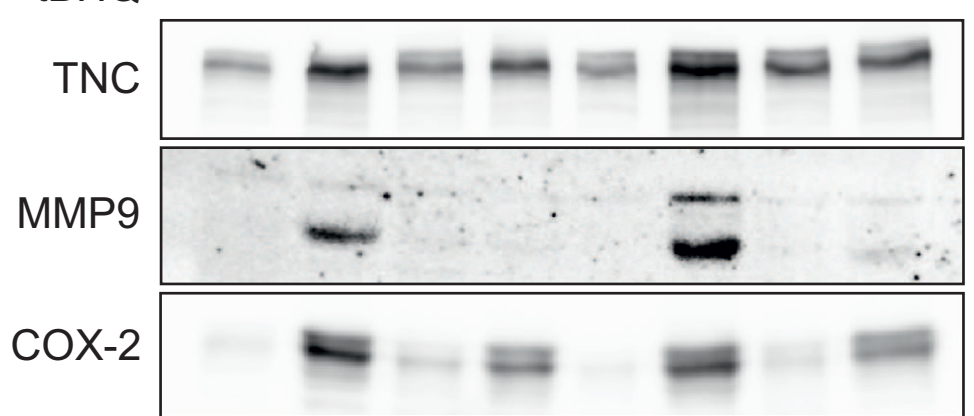

SMC1 $--\infty-\infty-\infty$

D

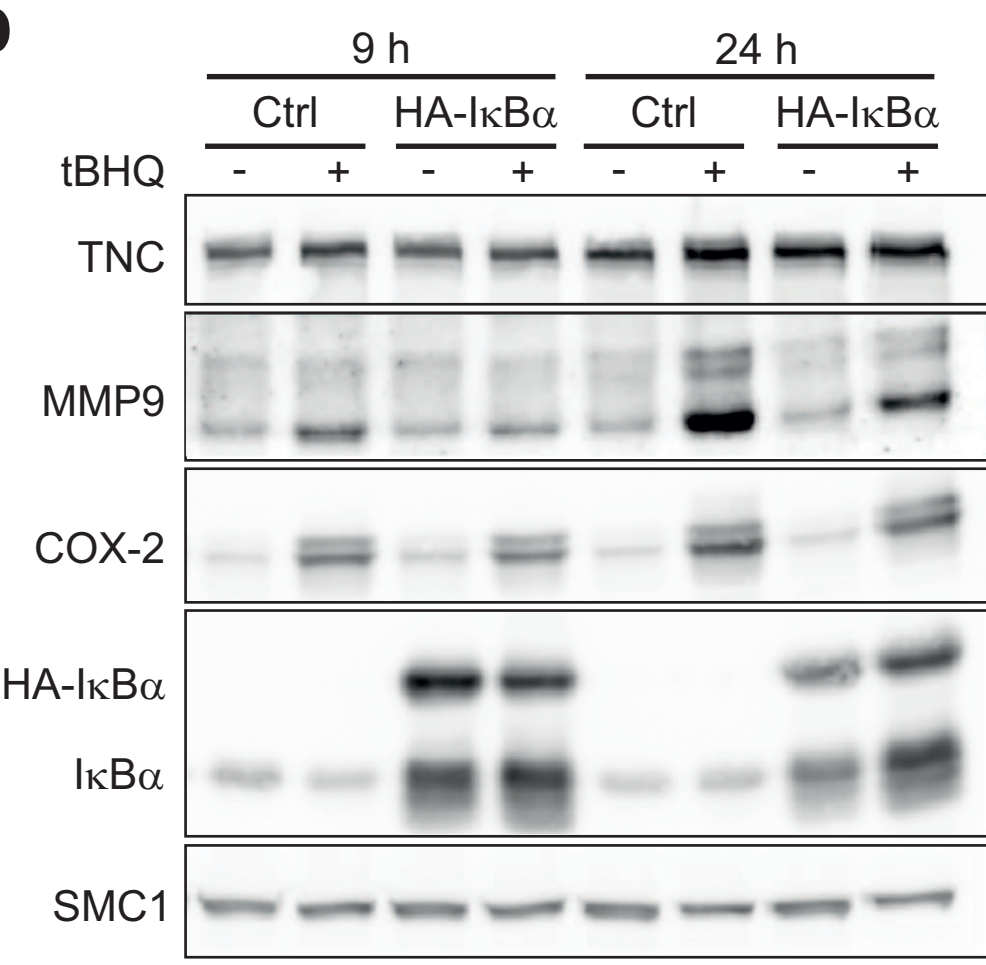

B

$\begin{aligned} \mathrm{BAY}(\mu \mathrm{M}) & \frac{0}{-+} \frac{12.5}{-+} \frac{25}{-+} \\ \mathrm{tBHQ} & \\ \mathrm{I} \mathrm{B} \alpha & \\ \mathrm{SMC} 1 & ----\infty\end{aligned}$

TNC

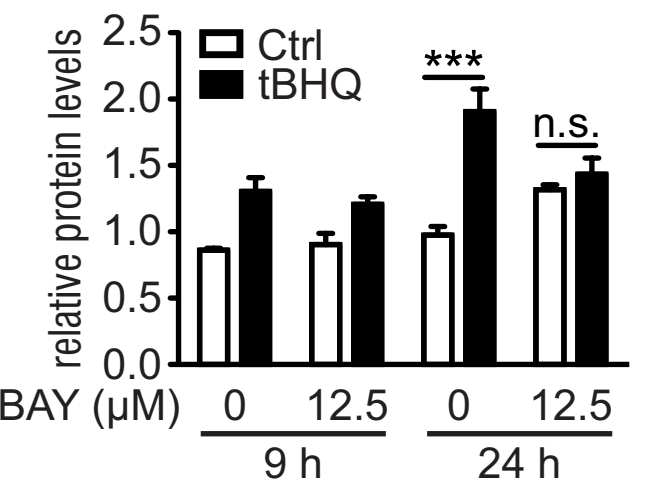

E

Ctrl

IL-1 $\beta$

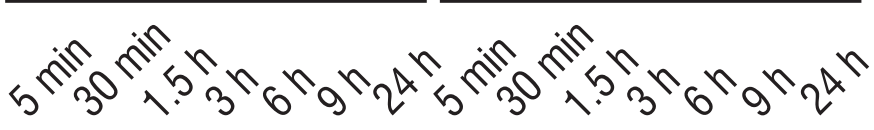

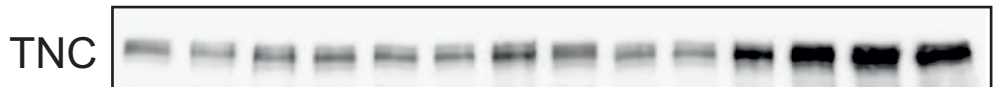

MMP9

cox-2

$=0$

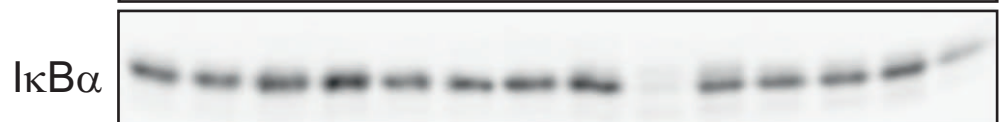

SMC1

F

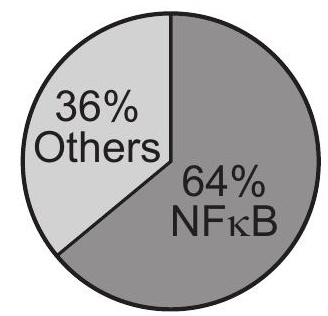




\section{Intermittent hypoxia}

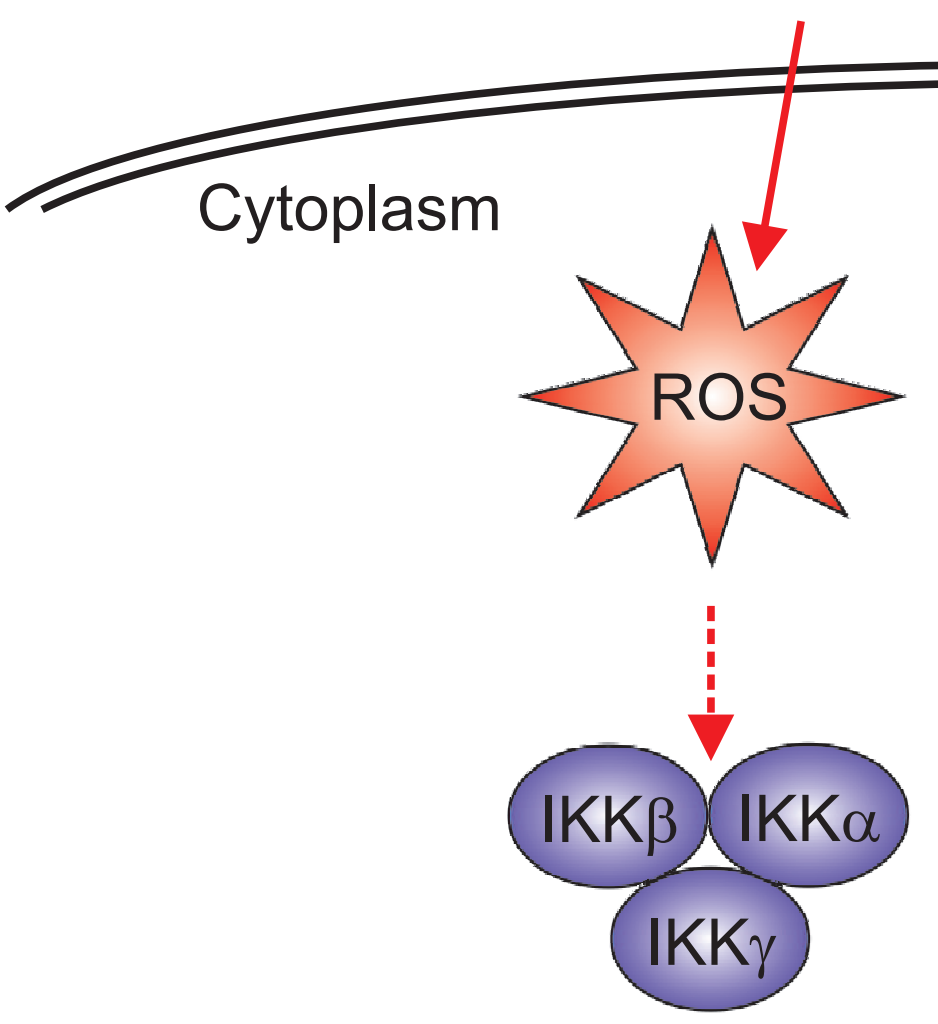

Inflammatory breast cancer cell
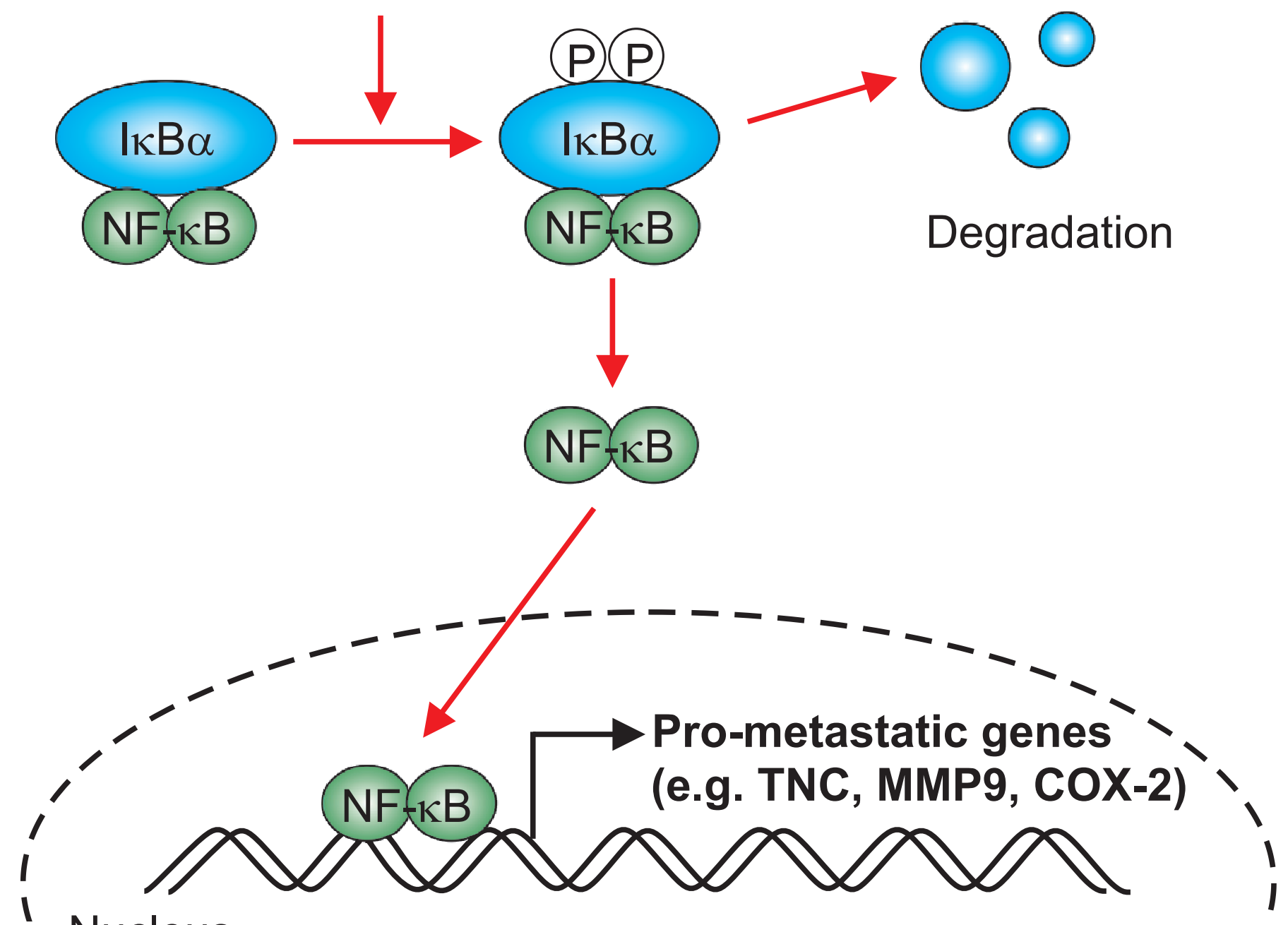

Nucleus 
Intermittent hypoxia

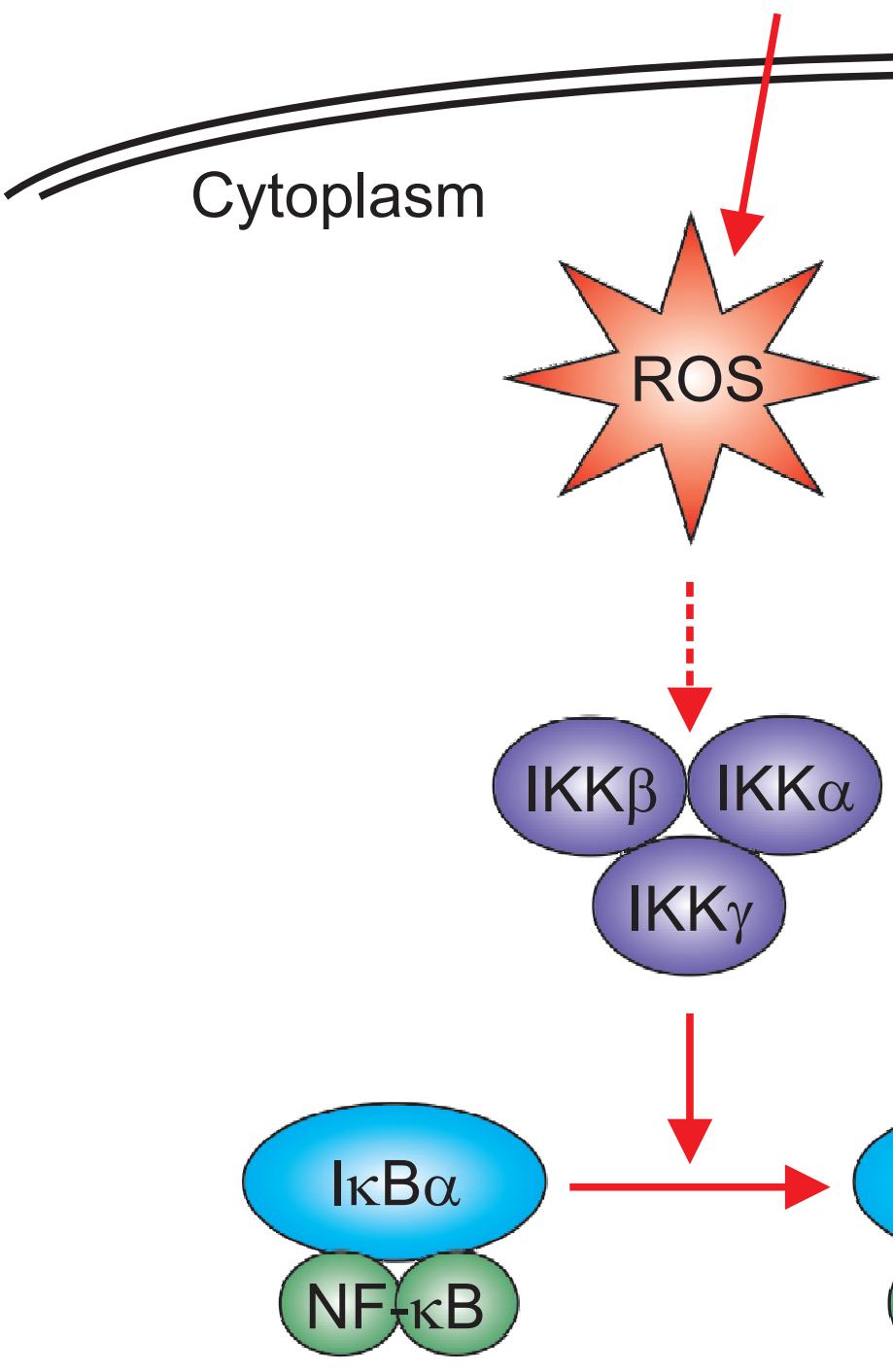

Inflammatory breast cancer cell

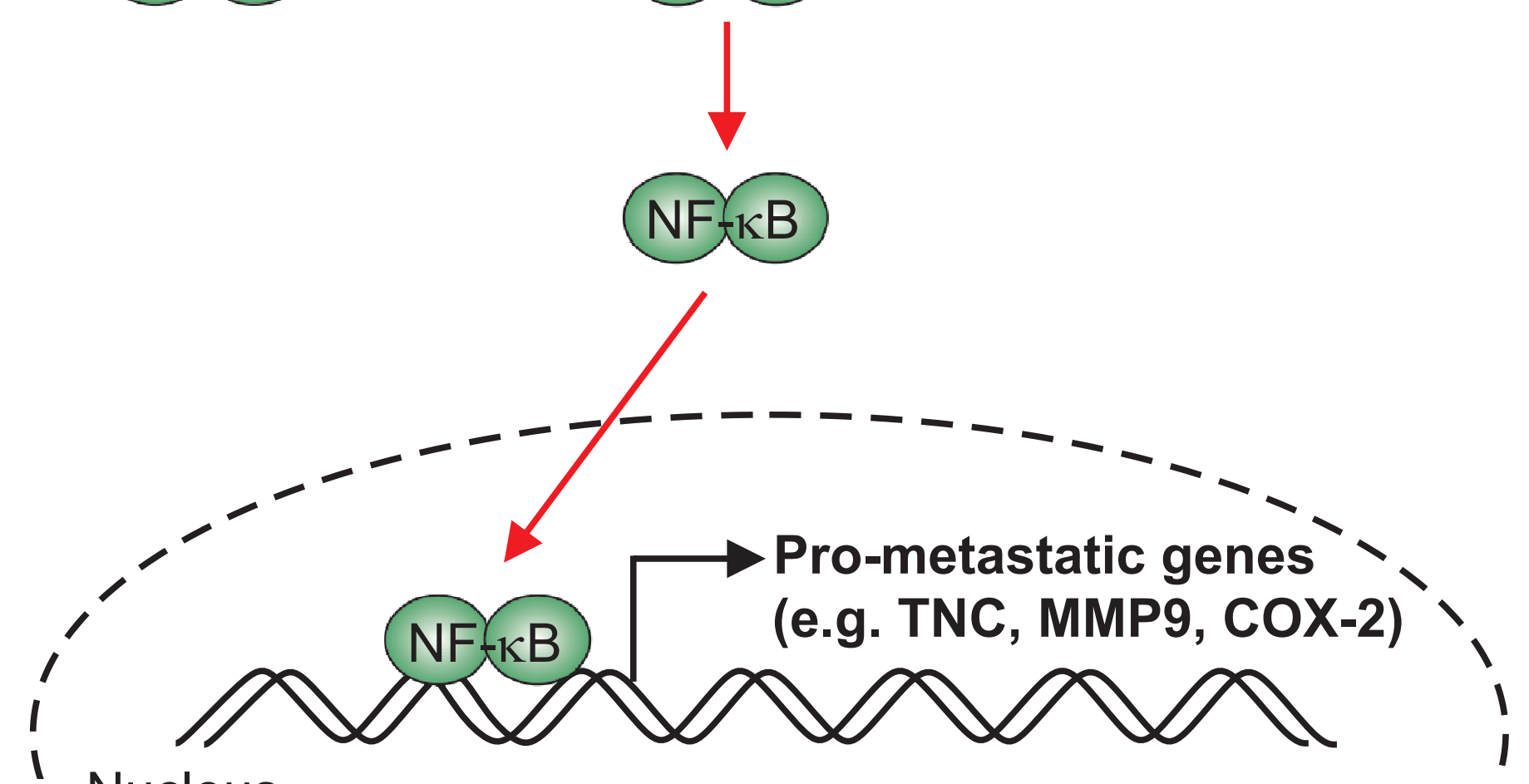

Nucleus

(P) (P)

$\mathrm{I} \kappa \mathrm{B} \alpha$

NFF

Degradation 